\title{
Optimal Multiobjective Control of Low-Voltage AC Microgrids: Power Flow Regulation and Compensation of Reactive Power and Unbalance
}

\author{
Danilo I. Brandao, Member, IEEE, Willian M. Ferreira, Augusto M. S. Alonso, Student, IEEE, \\ Elisabetta Tedeschi, Senior member, IEEE and Fernando P. Marafão, Member, IEEE
}

\begin{abstract}
The presence of single-phase distributed generators unevenly injecting active power in three-phase microgrids may create undesired upstream current unbalance. Consequently, voltage asymmetry and even active power curtailment may occur in such networks with negative economic impact. Thus, this paper proposes an optimal multiobjective approach to regulate the active and reactive power delivered by distributed generators driven by a three-layer hierarchical control technique in low-voltage microgrids. This method does not require previous knowledge of network parameters. The multiobjective algorithm is implemented in the secondary level achieving optimal dispatch in terms of maximizing the active power generation, as well as minimizing the reactive power circulation and current unbalance. By the existence of a utility interface three-phase converter placed at the point-ofcommon-coupling, the proposed control can regulate the power circulating among the microgrid phases, and the microgrid structure can withstand grid-connected and islanded operating modes. The path for interphase power circulation through the DClink of the utility interface allows the multiobjective algorithm to achieve better results in terms of generation and compensation compared to the system without utility interface. The proposed method is assessed herein by computational simulations in a threephase four-wire microgrid under realistic operational conditions.
\end{abstract}

Index Terms-Distributed generation, Microgrid, Multiobjective, Optimization, Power quality, unbalance.

\section{NOMENCLATURE}

$\begin{array}{ll}A_{G j} & \text { Nominal power of the } j \text {-th DER } \\ A_{U I} & \text { Nominal power of the UI } \\ \mathcal{B}_{m} & \text { Equivalent susceptance of phase } m \\ \mathcal{B}^{b} & \text { Equivalent three-phase susceptance } \\ F D & \text { PCC voltage unbalance index } \\ F G & \text { Active power generation factor } \\ F N_{a} & \text { Unbalance active power generation factor } \\ F N_{r} & \text { Unbalance reactive power generation factor } \\ F R_{N} & \text { Normalized reactive power factor } \\ G^{b}, G_{m} & \text { Equivalent three-phase and } m \text {-phase conductance } \\ \mathrm{H}(M) & \text { Downsampling LPF with } \pi / M \text { cutoff frequency } \\ k & \text { Control cycle counter of the PBC } \\ M & \text { Sampling rate of multiobjective algorithm } \\ N_{a}, N_{r} & \text { CPT unbalance active and reactive power } \\ P_{G j}, Q_{G j} & \text { Output active/reactive of power of the } j \text {-th DER }\end{array}$

This paragraph of the first footnote will contain the date on which you submitted your paper for review.

The authors are grateful to CAPES, CNPq (grant 420850/2016-3), FAPESP (grant 2017/24652-8 and 2016/08645-9), and the NFR (Grant f261735/H30).

D. I. Brandao is with the Graduate Program in Electrical Engineering, Federal University of Minas Gerais (UFMG), Brazil (dibrandao@ufmg.br).

W. M. Ferreira is with Federal Institute of Minas Gerais (IFMG), Campus of Ipatinga, Brazil (e-mail: willian.ferreira@ifmg.edu.br).

\begin{tabular}{|c|c|}
\hline$P_{G j}^{*}, Q_{G j}^{*}$ & Active/reactive power reference of the $j$-th DER \\
\hline$P_{G m t}, Q_{G m t}$ & Total active/reactive power processed by DERs at $m$-phase \\
\hline$P_{G m t}^{*}, Q_{G m t}^{*}$ & $\begin{array}{l}\text { Reference for the total active power processed by DERs at } \\
m \text {-phase }\end{array}$ \\
\hline$P_{G j}^{\max }, Q_{G j}^{\max }$ & Maximum generation capacity by the $j$-th DER \\
\hline$P_{G j}^{\min }$ & Maximum storage capacity by the $j$-th DER \\
\hline$P_{G m t}^{\max }, P_{G m t}^{\min }$ & Total maximum and minimum active power of DERs \\
\hline$Q_{G m t}^{\max }$ & Total maximum reactive power of DERs \\
\hline $\begin{array}{l}P_{\text {GRIDm }}, \\
Q_{\text {GRIDm }}\end{array}$ & Grid active/reactive power at $m$-phase \\
\hline $\begin{array}{l}P_{G R I D m}^{\max } \\
Q_{\text {GRIDm }}^{\max }\end{array}$ & Maximum grid active/reactive power capacity at $m$-phase \\
\hline $\begin{array}{l}P_{G R I D m}^{*} \\
Q_{G R I D m}^{*}\end{array}$ & $\begin{array}{l}\text { Reference of active/reactive power desired through the grid } \\
\text { at } m \text {-phase }\end{array}$ \\
\hline$P_{L m t}, Q_{L m t}$ & Total active/reactive power consumed by loads at $m$-phase \\
\hline$P_{L m}^{\max }, Q_{L m}^{\max }$ & Maximum load power values at $m$-phase \\
\hline$P_{U I m}, Q_{U I m}$ & Output active/reactive power of the UI at $m$-phase \\
\hline$P_{U I m}^{*}, Q_{U I m}^{*}$ & Reference for the UI active/reactive power at $m$-phase \\
\hline$P_{U I}^{\max }$ & Maximum active of power generated by the UI \\
\hline$P_{U I}^{\min }$ & Maximum capability to store active power by the UI \\
\hline$T$ & $\mathrm{PBC}$ time processing \\
\hline$T_{d}$ & Transmission ra \\
\hline $\boldsymbol{V}_{P C C}$ & Collective voltage value at the PCC \\
\hline$V_{P C C m}$ & RMS $m$-phase voltage value at the PCC \\
\hline$W$ & Weight of compensation factors \\
\hline$X_{m j}$ & Indicates $j$-th DER connected " 1 " or not " 0 " at $m$-phase \\
\hline$\alpha_{P m}$ & Scaling coefficient of active power for DERs at $m$-phase \\
\hline$\alpha_{Q m}$ & Scaling coefficient of reactive power for DERs at $m$-phase \\
\hline$\omega_{c}$ & Bandwidth of DER local controller \\
\hline$\gamma_{o}$ & Static gain of multiobjective algorithm \\
\hline
\end{tabular}

\section{INTRODUCTION}

$\mathrm{T}$ HE dense presence of power electronic converters without proper coordination may be detrimental in terms of power flow control, voltage regulation and power quality concerns [1], [2], particularly in low-voltage (LV) distribution power systems with dynamic behavior, such as microgrids (MGs).

In addition to the likely existence of unbalanced loads, the arbitrarily connected single-phase distributed energy resources (DERs), like PV rooftop systems, also impact on the imbalance/interphase power flow within LV MGs and upstream current unbalance at the MG's point of common coupling (PCC) [3]. Hence, power curtailment is required in most applications

F. P. Marafão and A. M. dos Santos Alonso are with the Group of Automation and Integrated Systems, São Paulo State University (UNESP), Sorocaba, Brazil (e-mail: \{fernando.marafao; augusto.alonso\}@unesp.br). A. M. dos Santos Alonso is also with the Dept. Electric Power Engineering, Norwegian University of Science and Technology (NTNU), Norway.

E. Tedeschi is with the Dept. Electric Power Engineering, Norwegian University of Science and Technology (NTNU), Norway (e-mail: elisabetta.tedeschi@ntnu.no). 
to limit voltage asymmetry among the system phases [4], which increases the cost of power generation. Thus, LV MG with heavy penetration of single-phase DERs randomly distributed among the phases is a challenging scenario in terms of: $i$ ) steering power into the grid; ii) efficiently exploiting DERs through power sharing; iii) operating in both grid-connected and islanded modes; and $i v$ ) optimally regulating the active power injection of DERs while using their surplus capability to tackle power quality issues.

\section{A. Literature Review}

In literature, most of the aforementioned MG operational challenges are overcome, in general, by centralized or decentralized approaches [3]-[8]. For instance, the authors of [4] propose a combined central and local power control to tune the regulation of dispersed single-phase PV inverters, taking into consideration the conflicting objectives of maximizing the active power injection and concomitantly reducing the voltage asymmetry. The continuous re-optimization of local reactive power injection and active power curtailment is devised through a convex optimization problem. Though it succeeds in maximizing the active power feed-in without exceeding standardized voltage thresholds, this method requires knowledge of the MG sensitivity matrix during its operation. Besides, mitigation of voltage unbalance is constrained to the curtailment of the active power generated by the PV inverters.

Centralized coordination of arbitrarily connected singlephase inverters (i.e., line-to-line and line-to-neutral connection) is proposed in [3]. It provides proportional sharing of active and reactive power among DERs according to their power capability, and mitigation of current unbalance. Such proposal is devised on power-based control (PBC) basis that is implemented at the secondary layer of a hierarchical $\mathrm{MG}$ control. However, the power generation and the compensation are not optimally controlled.

In [5], a hierarchical control employing a centralized optimal regulator devised at the tertiary layer is also proposed. It operates the droop controlled DERs in a day-ahead scheduling energy management, using a mixed-integer nonlinear programming as an extension of an optimal power flow formulation. However, this method depends on the prediction of load demand and generation capacity, as well as the knowledge of power line impedances. An extension of [5] is presented in [6] as a decentralized hierarchical control, on which a first-order consensus protocol is used to offer power sharing among DERs. In this case, DERs have their power references set by the solution of an optimal problem based on primal-dual constrained decomposition. Despite the inherent benefits of short-distance communication, neither grid power flow dispatch nor control of unevenly connected single-phase DERs are addressed.

A decentralized approach proposed in [7] focuses on having a DSTATCOM installed at the MG's PCC to mitigate reactive power and current unbalance by circulating power among the network's phases through its DC link. DERs are driven by constant PQ control when grid-connected, or following V/f droop control upon islanded MG operation. Thus, in addition to requiring multiple control approaches to ensure both operating modes, this work does not deal with optimal MG management. Interfacing converters have also been efficiently coordinated on hybrid AC/DC systems, based on virtual inertia and capacitance, to support power quality improvement and strengthen dynamic stability by means of power circulation through the converter's DC-link [8].

Finally, the authors of [9] propose a consensus-based distributed method that coordinates the single-phase PV inverters. It explores their local capability of processing reactive power, striving for voltage unbalance mitigation, as well as voltage regulation. The former goal is achieved by considering these DERs grouped in delta-connection and providing specified amounts of reactive power per phase. The latter is regulated by line-to-neutral inverters sharing reactive power. Besides diminishing current unbalance as consequence of voltage quality enhancement, this approach clusters DERs depending on their interconnection topology.

Some of the above-mentioned approaches, along with other relevant works found in the literature, are further explored in Table I, focusing on the matter of MG optimal control based on the coordination of DERs. Such literature review analysis aims at highlighting the main features of each proposal in terms of: i) the main issues tackled; $i$ ) how the cooperative control of DERs is implemented; iii) the grounds for the formulation of the optimization problem and its respective proposed solution method; $i v)$ the adopted MG network and topology of existing DERs; and $v$ ) the means of assessment of results. Secondly, this result intends to reinforce the contributions of the proposed method, which strives for an optimal multiobjective operation of LV MGs, considering single- and three-phase converters which are coordinated by a droop-free approach. Finally, most of the works using nonlinear/robust control take advantage of particle swarm optimization (PSO) to formulate the optimal problem. On the contrary, the method herein employs the MOEA/D as evolutionary genetic algorithm for the optimal formulation, inheriting its advantages/disadvantages over PSO.

\section{B. Contribution and Paper Organization}

Considering such challenging scenario of multiples singlephase inverters randomly distributed, this paper proposes an optimal multiobjective formulation that aims at maximizing the active power generation, and simultaneously minimizing the reactive power circulation and current unbalance. The goal is achieved by a master-slave architecture, endowed with a narrowband, low data rate communication link, and a centralized three-phase converter named utility interface (UI) [16] placed at the MG's PCC. The method focuses on current unbalance to indirectly mitigate the voltage unbalance without requiring previous knowledges of the MG parameters or prediction. The three-phase UI provides interphase power circulation, which contributes to the multiobjective approach achieving better results in terms of generation and compensation. Finally, the UI allows islanding operation of the whole MG.

This paper is an extension of [17], with further contributions on: i) applying the evolutionary multiobjective algorithm (MOEA/D) to optimally regulate power flow, and also compensate the reactive power and current unbalance using 
randomly connected single-phase DERs; ii) exploring the power circulation through its DC-link; and iii) evaluating the concomitant integration of the UI allowing the interphase proposed technique by simulation results on a real LV grid.

TABLE I

COMPARATIVE SUMMARY OF THE LITERATURE REVIEW ON OPTIMAL MG CONTROL.

\begin{tabular}{|c|c|c|c|c|c|c|c|c|}
\hline \multirow[b]{2}{*}{ Ref. } & \multicolumn{2}{|l|}{ Features } & \multicolumn{4}{|c|}{ Methodology } & \multirow{2}{*}{$\begin{array}{c}\text { Microgrid } \\
\text { Topology } \\
\text { and } \\
\text { \# of DERs }\end{array}$} & \multirow{2}{*}{$\begin{array}{r}\text { Results } \\
\text { Experi- } \\
\text { mental }\end{array}$} \\
\hline & Main Goals & $\begin{array}{l}\text { Power } \\
\text { Share }\end{array}$ & $\begin{array}{l}\text { Hierarc. } \\
\text { Architec. }\end{array}$ & $\begin{array}{l}\text { Control } \\
\text { Approach }\end{array}$ & $\begin{array}{c}\text { Optimization } \\
\text { Concept / } \\
\text { Algorithm } \\
\end{array}$ & $\begin{array}{l}\text { Use of } \\
\text { Comm. }\end{array}$ & & \\
\hline [4] & $\begin{array}{l}\text { Voltage regulation } \\
\text { Reduce curtailment of active } \\
\text { power } \\
\text { Reactive power control }\end{array}$ & No & No & $\begin{array}{l}\text { Local PQ control based on } \\
\text { first-order splines } \\
\text { (piecewise linear } \\
\text { functions) considering } \\
\text { DERs' ratings }\end{array}$ & $\begin{array}{l}\text { Convex } \\
\text { optimization }\end{array}$ & $\begin{array}{l}\text { Yes } \\
\text { (C) }\end{array}$ & $\begin{array}{l}\text { Radial }(3 \Phi) \\
62 \text { Nodes } \\
34 \text { DERs }\end{array}$ & No \\
\hline$[5]$ & $\begin{array}{l}\text { Regulation of power flow } \\
\text { Regulation of MG's frequency } \\
\text { and voltage magnitude } \\
\text { (unbalance) } \\
\text { Reduce curtailment of loads and } \\
\text { wind turbines }\end{array}$ & Yes & Yes & Droop control & $\begin{array}{l}\text { Mixed-integer } \\
\text { nonlinear } \\
\text { programming } \\
\text { Mixed-integer } \\
\text { linear } \\
\text { programming } \\
\end{array}$ & $\begin{array}{l}\text { No } \\
\text { (D) }\end{array}$ & $\begin{array}{l}\text { Radial }(3 \Phi) \\
\text { a) } 25 \text { Nodes } \\
8 \text { DERs } \\
\text { b) } 124 \text { Nodes } \\
10 \text { DERs }\end{array}$ & No \\
\hline$[6]$ & $\begin{array}{l}\text { Regulation of power flow } \\
\text { Regulation of MG's frequency } \\
\text { and voltage magnitude } \\
\text { (unbalance) } \\
\text { Reduction of operational cost }\end{array}$ & Yes & Yes & $\begin{array}{l}\text { Droop control } \\
\text { First-order consensus } \\
\text { protocol }\end{array}$ & $\begin{array}{l}\text { Primal-dual } \\
\text { constrained } \\
\text { decomposition }\end{array}$ & $\begin{array}{l}\text { Yes } \\
\text { (D) }\end{array}$ & $\begin{array}{l}\text { Radial }(3 \Phi) \\
25 \text { Nodes } \\
7 \text { DERs }\end{array}$ & No \\
\hline [10] & $\begin{array}{l}\text { Dynamic performance for small- } \\
\text { and large-signal disturbances } \\
\text { Improve Fault Ride Through } \\
\text { capability }\end{array}$ & Yes & Yes & $\begin{array}{l}\text { Droop control } \\
\text { Robust mixed } H_{i} / H_{\infty} \\
\text { control } \\
\text { Decentralized robust } \\
\text { servo-mechanism } \\
\text { Radial basis function } \\
\text { neural networks }\end{array}$ & $\begin{array}{l}\text { Linear/bilinear } \\
\text { matrix } \\
\text { inequalities } \\
\text { Convex } \\
\text { optimization }\end{array}$ & $\begin{array}{l}\text { Yes } \\
\text { (D) }\end{array}$ & $\begin{array}{l}\text { Radial }(3 \Phi) \\
13 \text { Nodes } \\
3 \text { DERs }\end{array}$ & $\begin{array}{c}\text { No* } \\
\text { HIL } \\
+ \\
\text { FPGA }\end{array}$ \\
\hline [11] & $\begin{array}{l}\text { Dynamic performance for small- } \\
\text { and large-signal disturbances } \\
\text { Improve Fault Ride Through } \\
\text { capability }\end{array}$ & Yes & Yes & $\begin{array}{l}\text { Droop control } \\
\text { Robust mixed } H_{i} / H_{\infty} \\
\text { control } \\
\text { Radial basis function } \\
\text { neural networks }\end{array}$ & $\begin{array}{l}\text { Linear/bilinear } \\
\text { matrix } \\
\text { inequalities } \\
\text { Multiobjective } \\
\text { particle swarm } \\
\text { optimization } \\
\text { Fuzzy decision- } \\
\text { making tool }\end{array}$ & $\begin{array}{l}\text { Yes } \\
\text { (D) }\end{array}$ & $\begin{array}{l}\text { Radial }(3 \Phi) \\
13 \text { Buses } \\
3 \text { DERs }\end{array}$ & $\begin{array}{c}\text { No* } \\
\text { HIL } \\
+ \\
\text { FPGA }\end{array}$ \\
\hline [12] & $\begin{array}{l}\text { Increase MG stability margins } \\
\text { under large-signal disturbances } \\
\text { Improve power sharing in hybrid } \\
\text { MGs under nonlinear and } \\
\text { unbalanced loads }\end{array}$ & Yes & Yes & $\begin{array}{l}\text { Droop control } \\
\text { Positive and negative } \\
\text { power sequence power } \\
\text { control through sliding } \\
\text { mode control } \\
\text { Lyapunov function } \\
\text { Radial basis function } \\
\text { neural networks }\end{array}$ & $\begin{array}{l}\text { Multiobjective } \\
\text { particle swarm } \\
\text { optimization }\end{array}$ & $\begin{array}{l}\text { Yes } \\
\text { (D) }\end{array}$ & $\begin{array}{l}\text { Hybrid } \\
\text { AC/DC }(3 \Phi) \\
3 \text { DERs at } \\
\text { DC side }\end{array}$ & $\begin{array}{c}\text { No* } \\
\text { HIL } \\
+ \\
\text { FPGA }\end{array}$ \\
\hline [13] & $\begin{array}{l}\text { Regulation of power flow } \\
\text { Unbalanced harmonic power } \\
\text { sharing } \\
\text { Voltage Regulation }\end{array}$ & Yes & Yes & $\begin{array}{l}\text { Droop control } \\
\text { Harmonic virtual } \\
\text { impedance } \\
\text { Radial basis function } \\
\text { neural networks }\end{array}$ & $\begin{array}{l}\text { Orthogonal } \\
\text { least-square } \\
\text { algorithm } \\
\text { Exact fit method }\end{array}$ & $\begin{array}{l}\text { Yes } \\
\text { (D) }\end{array}$ & $\begin{array}{l}\text { Radial }(3 \Phi) \\
4 \text { Nodes } \\
4 \text { DERs }\end{array}$ & $\begin{array}{l}\text { No* } \\
\text { HIL }\end{array}$ \\
\hline [14] & $\begin{array}{l}\text { Reduction of voltage unbalance } \\
\text { Restoration of frequency and } \\
\text { voltage deviation }\end{array}$ & Yes & Yes & $\begin{array}{l}\text { Droop control } \\
\text { Virtual impedance }\end{array}$ & $\begin{array}{l}\text { Single-objective } \\
\text { optimization } \\
\text { Genetic } \\
\text { algorithm }\end{array}$ & $\begin{array}{l}\text { Yes } \\
\text { (C) }\end{array}$ & $\begin{array}{l}\text { Radial }(3 \Phi) \\
6 \text { Nodes } \\
2 \text { DERs }\end{array}$ & $\begin{array}{l}\text { No* } \\
\text { HIL }\end{array}$ \\
\hline [15] & $\begin{array}{l}\text { Regulation of power flow } \\
\text { Improve global efficiency } \\
\text { Voltage regulation }\end{array}$ & Yes & Yes & $\begin{array}{l}\text { Droop control } \\
\text { Extended optimal power } \\
\text { flow control level }\end{array}$ & $\begin{array}{l}\text { Single-objective } \\
\text { optimization } \\
\text { Nonlinear } \\
\text { programming }\end{array}$ & $\begin{array}{l}\text { Yes } \\
\text { (C) }\end{array}$ & $\begin{array}{l}\text { Radial }(3 \Phi) \\
3 \text { Nodes } \\
3 \text { DERs }\end{array}$ & Yes \\
\hline Here & $\begin{array}{l}\text { Regulation of power flow } \\
\text { Reduction of reactive power and } \\
\text { current unbalance } \\
\text { Consideration of randomly } \\
\text { connected } I \Phi \text { DERs }\end{array}$ & Yes & Yes & $\begin{array}{l}\text { Model-Free Power-Based } \\
\text { Control (PBC) }\end{array}$ & $\begin{array}{l}\text { Multiobjective } \\
\text { optimization } \\
\text { MOEA/D } \\
\text { Vikor method }\end{array}$ & $\begin{array}{l}\text { Yes } \\
\text { (C) }\end{array}$ & $\begin{array}{l}\text { Radial } \\
(1 \Phi+3 \Phi) \\
26 \text { Nodes } \\
8 \text { DERs }\end{array}$ & No \\
\hline
\end{tabular}

*Although results are attained by means of hardware-in-the-loop (HIL) tools, only real-time simulations were performed. The work does not present any kind of experimental validation by means of a prototype setup comprising power switching devices, power sources or loads. (C): centralized, (D) decentralized approach.

\section{Microgrid TOPOLOGY AND CONTROL ARCHITECTURE}

To evaluate the proposed optimal multiobjective control method, a three-phase four-wire metropolitan distribution network with overhead power lines is adopted (Fig. 1). It is based on $220 \mathrm{~V}$ (line-to-line) at the secondary side of the deltawye coupling transformer, and comprises line impedances and loads unevenly distributed among the phases, as described in [18]. Besides, six dispersed single-phase DERs (phase $a$ : 
$\mathrm{DER}_{\mathrm{N} 15}$ and $\mathrm{DER}_{\mathrm{N} 26}$; phase $b$ : $\mathrm{DER}_{\mathrm{N} 4}$ and $\mathrm{DER}_{\mathrm{N} 12}$; and phase $c: \mathrm{DER}_{\mathrm{N} 7}$ and $\mathrm{DER}_{\mathrm{N} 21}$, where "N" represents the node) are included, and a three-phase UI converter is placed at the MG's PCC. The UI operates with a triple-loop control (currentvoltage-current), acting as grid-forming converter under islanded mode, and as grid-supporting while the MG is interconnected to the mains, providing smooth transition between both modes [16]. Yet, through the DC link of UI a path is created to circulate power among phases. Although harmonic compensation is also achievable by the UI [16], it is not addressed herein.

The hierarchical master-slave control architecture is defined by having a master controller (MC), which is placed at the MG's PCC, that cooperatively drives the slave agents (i.e., DERs) through a narrowband, low data rate communication infrastructure. A cyclical control process is implemented by gathering and processing information related to the average power processed by DERs, as well as the ones drawn from the main grid in the MC, and later broadcasting scaling coefficients to DERs to coordinate them. The need of bidirectional communication infrastructure can be fulfilled by communication means of limited performance, and it can be resiliently implemented by distributed hubs [19] under interoperability standards such as the IEC 61850 [20].

Fig. 2 shows the hierarchical layers and their control loops established into three levels. The first level, which runs with frequencies of $\mathrm{kHz}$, is responsible for the local control of DERs and UI, i.e., their basic, specific and ancillary functions. Typical examples are grid-support functions such as voltage, reactivepower or frequency regulation, which are implemented in the local controllers of DERs [21]. This level is resilient to communication failures, meaning that converters are able to redirect their operational goals from a cooperative approach to local objectives, complying with grid codes and standards. Those converters must be power dispatchable either in current or voltage control mode [22], [23]. Currently, solutions of remotely dispatchable inverters are found commercially [24], [25], sometime through a dedicated power control module [26]. The non-dispatchable sources, e.g., PV sources and conventional droop-controlled converters, do not contribute to the power sharing and global operation of the MG secondarylevel. Since the primary level is consolidated in the literature [2], it is not further addressed herein.

The secondary level is fully implemented in the MC, using a communication link to gather/broadcast data from/to DERs, respectively. This level is split into two processing layers that exchange data. The first layer (i.e., layer-1) operates within millisecond-timescale (i.e., around the fundamental frequency of the grid voltage) and manages the short-term energy variation, e.g., generation/load change and power quality enhancement. The second layer (i.e., layer-2) operates within the second-timescale and copes with the middle-term energy variation, setting reactive/unbalance setpoints. The former is based on the $\mathrm{PBC}$ and ensures compliance with the MG requirements. As stated in Section I, it does not require any previous knowledge of the network topology and parameters. Section II-A goes through this algorithm, i.e., PBC. The latter is the multiobjective formulation problem that is the main contribution of this paper, and sets the steady-state grid power references based on the MG status and inputs from the third hierarchical level. Section III details the multiobjective optimization problem formulation and the algorithm solver.

The tertiary level is the slowest one (few minutes). This level is committed to manage the interaction between the MG and the utility, in terms of maximum and minimum active/reactive power flow constraints based on the system hosting capacity. It relies on a unidirectional high-security communication path linked to the distribution system operator (DSO) and the MG.

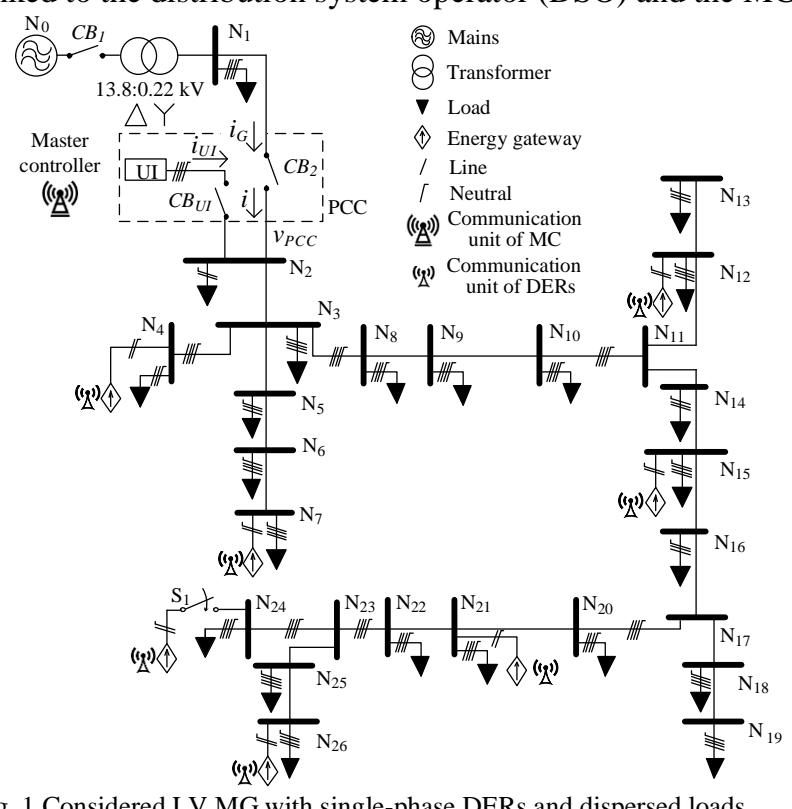

Fig. 1 Considered LV MG with single-phase DERs and dispersed loads.

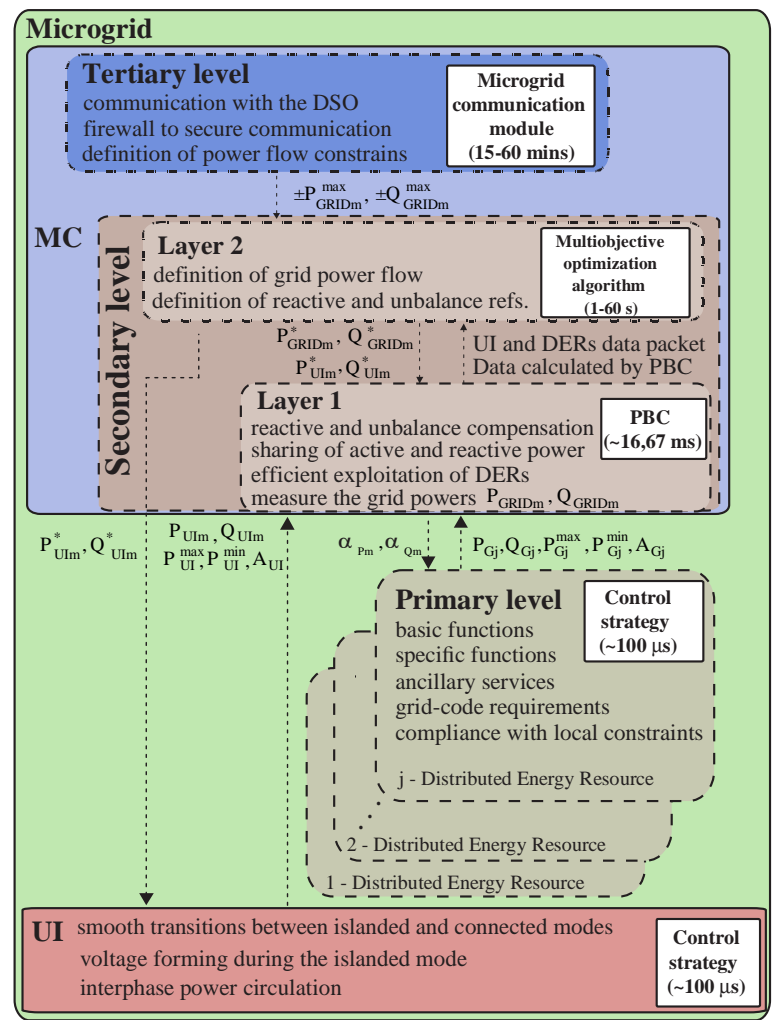

Fig. 2 Hierarchical control strategy based on PBC and multiobjective problem. 


\section{A. Model-Free Power-Based Control}

The $\mathrm{PBC}$ is a robust method against parameters variation that provides coordination of DERs within a MG through the manipulation of average power quantities. In [3], the PBC is proposed to flexibly accommodate arbitrary connected singlephase DERs (i.e., line-to-line or line-to-neutral inverters) in a three-phase four-wire network. It achieves $i$ ) grid power flow control; ii) proportional sharing of power among DERs; iii) both grid-connected and islanded operating modes; and $i v$ ) high level of power quality to the grid exploiting the DERs surplus power capacity. Such control concept reaches low values of distribution power loss [27].

The PBC runs in the MC according to the following described steps, presenting as outcome the calculation of coefficients $\left(\alpha_{P_{m}}, \alpha_{\varrho m}\right)$ that modulate the active and reactive power injection of DERs.

Considering the scheme in Fig. 2, and taking the subscript $m$ as generic phase index (i.e., $m=a, b$ or $c$ ), the PBC operates by:

Step 1: the MC gathers, at the beginning of a control cycle $k$, a data packet from each $j$-th DER $(j=1,2, \ldots, J)$ and UI, consisting of: 1 ) actual output active power, $P_{G j}(k)$ and $P_{U I m}(k)$, of the DERs and UI, respectively; 2) actual reactive power, $Q_{G j}(k)$ and $\left.Q_{U I m}(k) ; 3\right)$ maximum active power that can be generated, $P_{G j}^{\max }(k)$ and $\left.P_{U I}^{\max }(k) ; 4\right)$ if available, maximum capability to store active power, $P_{G j}^{\min }(k)$ and $P_{U I}^{\min }(k)$, given as a positive value; and 5) nominal (apparent) power of the converters, $A_{G j}(k)$ and $A_{U I}(k)$.

To properly perform the current unbalance compensation, the MC must know the DER's $m$-phase connection. Thus, when a DER is installed, and its owner desires it to be included in the provision of cooperative ancillary services, its inclusion in the PBC participating list has to be requested [4].

Step 2: by measuring the grid-side PCC active $\left(P_{\text {GRIDm }}(k)\right)$ and reactive $\left(Q_{G R I D m}(k)\right)$ power, the MC calculates:

Step 2.1: the total active $\left(P_{G m t}\right)$ and reactive $\left(Q_{G m t}\right)$ power per phase provided by DERs for the $k$-th control cycle. Considering $X_{m j}$ as a binary variable indicating if the $j$-th DER is connected (i.e., equals to 1 ) or disconnected (i.e., equals to 0 ) to phase $m$.

$$
\begin{aligned}
& P_{G m t}(k)=\sum_{j=1}^{J} P_{G j}(k) * X_{m j} \\
& Q_{G m t}(k)=\sum_{j=1}^{J} Q_{G j}(k) * X_{m j}
\end{aligned}
$$

Likewise, the MC computes the total minimum and maximum active power, $P_{G m t}^{\min }(k)$ and $P_{G m t}^{\max }(k)$, and the total maximum reactive power $Q_{G m t}^{\max }(k)$ per phase. The maximum reactive power that the $j$-th DER can process is given by (3):

$$
Q_{G j}^{\max }(k)=\sqrt{A_{G j}(k)^{2}-P_{G j}(k)^{2}}
$$

Step 2.2: the total active and reactive power consumed by the MG in control cycle $k$ is attained from power balance.

$$
\begin{aligned}
& P_{\text {Lmt }}(k)=P_{\text {GRIDm }}(k)+P_{\text {Gmt }}(k)+P_{\text {UIm }}(k) \\
& Q_{\text {Lmt }}(k)=Q_{G R I D m}(k)+Q_{G m t}(k)+Q_{U I m}(k)
\end{aligned}
$$

Note that the DERs not enrolled on the PBC (like nondispatchable sources), and the distribution power losses through line impedances are considered in $P_{L m t}(k)$.
Step 2.3: firstly, the $m$-phase active and reactive power references for the main grid and UI in the next control cycle $(k+1), \quad P_{G R I D m}^{*}(k+1), \quad Q_{G R I D m}^{*}(k+1), \quad P_{U I m}^{*}(k+1), \quad$ and $Q_{U I m}^{*}(k+1)$, respectively, are attained from the multiobjective optimization. Secondly, the desired active and reactive power to be shared among the DERs, $P_{G m t}^{*}(k+1)$ and $Q_{G m t}^{*}(k+1)$, are calculated by (6) and (7), based on the MG consumption power in the last control cycle $k$.

$$
\begin{aligned}
& P_{G m t}^{*}(k+1)=P_{L m t}(k)-P_{U I m}^{*}(k+1)-P_{G R I D m}^{*}(k+1) \\
& Q_{G m t}^{*}(k+1)=Q_{\text {Lmt }}(k)-Q_{U I m}^{*}(k+1)-Q_{G I D m}^{*}(k+1)
\end{aligned}
$$

Step 2.4: finally, the per phase scaling coefficients, $\alpha_{P m}$ and $\alpha_{Q m}$ (both in the range $[-1,1]$ ), are calculated from (8)-(10) and broadcasted to every DERs contributing to the PBC. Such coefficients are used by DERs to coordinate, respectively, their active and reactive power injection as given by Step 3. Positive and negative values of $\alpha_{P m}$ and $\alpha_{Q m}$ represent injection or absorption of active power, and inductive or capacitive reactive power processing, respectively.

$$
\begin{gathered}
\alpha_{P m}=\frac{P_{G m t}^{*}(k+1)}{P_{G m t}^{\max }(k)}, \quad \text { if } P_{G m t}^{*}(k+1)>0 \\
\alpha_{P m}=\frac{P_{G m t}^{*}(k+1)}{P_{G m t}^{\min }(k)}, \quad \text { if } P_{G m t}^{*}(k+1)<0 \\
\alpha_{Q m}=\frac{Q_{G m t}^{*}(k+1)}{Q_{G m t}^{\max }(k)}
\end{gathered}
$$

Step 3: locally, the active and reactive power references of DERs are calculated, by (11)-(12) and (13), respectively:

$$
\begin{gathered}
P_{G j}^{*}=\alpha_{P m} * P_{G j}^{\max }, \quad \text { if } P_{G m t}^{*}(k+1)>0 \\
P_{G j}^{*}=\alpha_{P m} * P_{G j}^{\min }, \quad \text { if } P_{G m t}^{*}(k+1)<0 \\
Q_{G j}^{*}=\alpha_{Q m} * Q_{G j}^{\max }
\end{gathered}
$$

\section{Optimal Multiobjective CONTROL OF MicrogridS}

The proposed optimal multiobjective control runs at the MC and considers grid power dispatch and compensation of reactive power and current unbalance.

\section{A. Formulation of Multiobjective Cost Functions}

Optimization problems depend on the definition of cost functions that describe parameters responsible for certain desired objectives. In this case, the quantities of interest are defined through four factors related to: active power generation $(F G)$, active (power) unbalance $\left(F N_{a}\right)$, reactive (power) unbalance $\left(F N_{r}\right)$ and normalized reactive power $\left(F R_{N}\right)$. The first, generation factor $(F G)$, is a ratio that measures how much of the available power is being injected into the grid (e.g., $F G$ is less than one in case of generation power curtailment). It is given by the total active power injected by DERs, considering all the three phases, over the maximum available power (14). An ideal solution aims at maximizing the $F G=1$.

$$
F G=\frac{\sum_{m=1}^{3} P_{G m t}^{*}(k+1)}{\sum_{m=1}^{3} P_{G m t}^{\max }(k)}
$$

The conservative power theory (CPT) [28] defines the factors $F N_{a}$ and $F N_{r}$. The former (15) indicates unbalance caused by current terms in-phase with the corresponding voltages (e.g., unbalanced resistive loads in $3 \Phi 4 \mathrm{~W}$ circuits). $\boldsymbol{V}_{P C C}(k)$ and $V_{P C C m}(k)$ stand for the PCC collective and $m$-phase rms voltages, respectively. $G_{m}$ is the equivalent conductance per phase and $G^{b}$ is equivalent three-phase conductance, given by 
(17) and (18).

$$
\begin{gathered}
F N_{a}=\frac{N_{a}}{\sqrt{\left[\sum_{m=1}^{3} P_{G R I D m}^{*}(k+1)\right]^{2}+N_{a}^{2}}}=\frac{N_{a}}{\sqrt{P_{G R I D t}^{*}(k+1)^{2}+N_{a}^{2}}} \\
N_{a}=V_{P C C}(k)^{2} \sqrt{\sum_{m=1}^{3} G_{m}^{2}-\left(G^{b}\right)^{2}} \\
G_{m}=\frac{P_{G R I D m}^{*}(k+1)}{V_{P C C m}(k)^{2}}=\frac{P_{L m t}(k)-P_{G m t}^{*}(k+1)-P_{U I m}^{*}(k+1)}{V_{P C C m}(k)^{2}} \\
G^{b}=\frac{P_{G R I D t}^{*}(k+1)}{V_{P C C}(k)^{2}}
\end{gathered}
$$

The latter, $\left(F N_{r}\right)$ represents unbalance resulting from current terms orthogonal to the voltages (e.g., unbalanced inductive/capacitive load), being related to susceptance terms $\left(\mathcal{B}_{m}\right.$ and $\left.\mathcal{B}^{b}\right) . \mathcal{B}_{m}=Q_{G R I D m}^{*}(k+1) / V_{P C C m}(k)^{2}$ is the equivalent susceptance per phase, and $\mathcal{B}^{b}=Q_{G R I D t}(k+1) / \boldsymbol{V}_{P C C}(k)^{2}$ is the equivalent three-phase quantity.

$$
\begin{gathered}
F N_{r}=\frac{N_{r}}{\sqrt{Q_{G R I D t}^{*}(k+1)^{2}+N_{r}^{2}}} \\
N_{r}=\boldsymbol{V}_{P C C}(k)^{2} \sqrt{\sum_{m=1}^{3} \mathcal{B}_{m}^{2}-\left(\mathcal{B}^{b}\right)^{2}}
\end{gathered}
$$

The $F R_{N}$ quantifies the reactive power flowing through the grid. It is a ratio of the total reactive power circulating in the grid-side of PCC and the reactive power consumed by the loads, where, $Q_{G R I D m}^{*}(k+1)=Q_{L m t}(k)-Q_{G m t}^{*}(k+1)-Q_{U I m}^{*}(k+1),(7)$ :

$$
F R_{N}=\frac{Q_{G R I D t}^{*}(k+1)}{\sum_{m=1}^{3} Q_{\text {Lmt }}(k)}=\frac{\sum_{m=1}^{3} Q_{G R I D m}^{*}(k+1)}{\sum_{m=1}^{3} Q_{\text {Lmt }}(k)}
$$

With the exception of $F G$, the optimization of the system should strive for reactive power and current unbalance as low as possible, meaning minimization of $F N_{a}, F N_{r}$ and $F R_{N}$. Thus, the multiobjective optimization problem is formulated by two sets of objective functions. The first deals with active power that aims at maximizing $F G$ and minimizing $F N_{a}(22)$. Note that since optimal problems are generally solved by minimization, when have then set " $-F G$ " on the objective function. These cost functions present constraints due to the converters (i.e., DERs and UI) power limits, main grid power flow capacity (i.e., $P_{G R I D m}^{\max }, Q_{G R I D m}^{\max }$ indicated by DSO) and energy balance during island operation, resulting in (23).

$$
\min _{P_{U I m}^{*}(k+1), P_{G m t}^{*}(k+1)}\left[-F G, F N_{a}\right]
$$

subject to:

$$
\begin{gathered}
P_{G m t}^{\min }(k) \leq P_{G m t}^{*}(k+1) \leq P_{G m t}^{\max }(k) \\
-\frac{A_{U I}^{\max }(k)}{3} \leq P_{U I m}^{*}(k+1) \leq \frac{A_{U I}^{\max }(k)}{3} \\
-P_{U I}^{\min }(k) \leq \sum_{m=1}^{3} P_{U I m}^{*}(k+1) \leq P_{U I}^{\max }(k) \\
-P_{G R I D m}^{\max }(k) \leq P_{G R I D m}^{*}(k+1) \leq P_{G R I D m}^{\max }(k) \\
P_{L m t}(k)=P_{G R I D m}^{*}(k+1)+P_{G m t}^{*}(k+1)+P_{U I m}^{*}(k+1)
\end{gathered}
$$

The terms corresponding to the reactive power are then processed subsequently minimizing $F R_{N}$ and $F N_{r}$ (24). $Q_{G m t}^{*}(k+1)$ and $Q_{U I m}^{*}(k+1)$ are constrained as in $(25)$, based on the surplus power capacity of converters or required standards compliance. It is important to highlight that, by solving the optimization problem in two sequential stages, active power injection takes precedence over reactive (balanced and unbalanced) compensation.

$$
\min _{Q_{U I m}^{*}(k+1), Q_{G m t}^{*}(k+1)}\left[F R_{N}, F N_{r}\right]
$$

subject to:

$$
\begin{gathered}
\left|Q_{G m t}^{*}(k+1)\right| \leq \sqrt{A_{G m t}(k)^{2}-P_{G m t}^{*}(k+1)^{2}} \\
\left|Q_{U I m}^{*}(k+1)\right| \leq \sqrt{\frac{A_{U I}(k)^{2}}{3}-P_{U I m}^{*}(k+1)^{2}} \\
-Q_{G R I D m}^{\max }(k) \leq Q_{G R I D m}^{*}(k+1) \leq Q_{G R I D m}^{\max }(k) \\
Q_{\text {Lmt }}(k)=Q_{G R I D m}^{*}(k+1)+Q_{G m t}^{*}(k+1)+Q_{U I m}^{*}(k+1)
\end{gathered}
$$

\section{B. Multiobjective Optimization Algorithm}

To obtain the optimal solutions for the formulated problem dealing with a set of objectives and constraints, under the consideration of conflicting goals, it is required to pre-establish the importance of each objective function. It can be solved by $a$ priori preference articulation (e.g., by a set of weights that is considered in the objective functions) or by a posteriori preference articulation through a multi-criteria decision making method [29]. Then, the a posteriori preference articulation has been chosen herein because it works better with non-convex problems [29].

In this paper, $F G$ conflicts with other factors due to the nature of the power system with single-phase inverters and loads. The multiobjective optimization algorithm is not able to achieve a single solution that simultaneously optimizes all cost functions. Such problem requires the solution of multiple objectives within a set of infinite possibilities, then the optimization algorithm must cover multimodal and non-convex concepts [30], [31]. In such cases, the approaches based on metaheuristic optimization and a posteriori preference articulation, particularly focused on genetic algorithms (GAs), are widely used in literature [31], [32]. Yet, a pareto-optimal GA estimates the pareto-optimal set of solutions by means of the dominance criteria, then a decision-making method is applied to select the most appropriate solution among a set of weights $(W)$ [30], [33]. Finally, this paper uses a multiobjective evolutionary approach based on decomposition (MOEA/D) [31] as GA, along with the Vikor method [33] as decision-maker.

The MOEA/D algorithm solves a multiobjective problem by decomposing it into several mono-objectives, thereupon optimizing them simultaneously [31]. It estimates a paretooptimal set, which is a set of feasible solutions that form a front in the objective space. It is worth mentioning that the MOEA/D algorithm is suitable for this application because of its ability to outperform and provide lower computational efforts than other GA methods [34]. Moreover, confronting with the NSGA-II method studied in [17], it offers faster convergence and more uniform solutions at the pareto-optimal front, as well as better test-retest reliability.

Upon the estimation of reasonable solutions from the MOEA/D, the Vikor decision-maker ranks the objective factors in a priority list based on the weights, $W$, providing the outcome of the multiobjective problem, which is given by power references for the UI (i.e., $P_{U I m}^{*}(k+1)$ and $\left.Q_{U I m}^{*}(k+1)\right)$ and DER contributions (i.e., $P_{G m t}^{*}(k+1)$ and $\left.Q_{G m t}^{*}(k+1)\right)$. 
Basically, this method assesses how close the solutions are to the ideal point [33], and picks the closest one. The authors of [33] have evaluated the Vikor method against other conventional decision-makers, and have concluded that the Vikor method shows lower computational processing and timeconsumption. Moreover, due to the non-convex characteristic of the pareto-optimal front formed in this application case, the weight of the decision-making strategy ( $v)$, named "the majority of criteria" [33], is set equal to zero.

Finally, the optimal power terms are applied to (6) and (7), at the secondary-level layer-2, resulting in optimal values to grid power references (i.e., $P_{G R I D m}^{*}(k+1)$ and $Q_{G R I D m}^{*}(k+1)$ ). Afterwards, the grid and UI power references are passed from the layer-2 on to the PBC algorithm (secondary-level layer-1) and to the UI converter. The cycle ends with the calculation of the scaling coefficients $\left(\alpha_{P m}\right.$ e $\left.\alpha_{Q m}\right)$, and their broadcasting to every participating DERs.

\section{Stability ANALysis}

This section presents the stability analysis of the microgrid control approach based on the secondary-level implementation. A simplified block diagram representing the main operations of the PBC and the multiobjective approach for what concerns active power balance is shown in Fig. 3 and a corresponding scheme can be derived for reactive power control. Time-delay is an inherent part of communication between MC and DERs, $\mathrm{T}^{\prime}$, and vice-versa, $\mathrm{T}^{\prime \prime}$, and it is included to take into account the phase margin deviation and to assess system stability.

Fig. 3(a) highlights the multiobjective algorithm (blue area) that is processed with a sampling rate $M$ times lower than the PBC time processing, $T$. The downsampling performs as an ideal lowpass filter (LPF) with cutoff frequency of $\pi / M, \mathrm{H}(M)$, and when followed by compression, $\mathrm{M} \downarrow$, has been called decimation. The variable $\gamma_{o}$ represents the static gain of the multiobjective algorithm. Fig. 3(b) is employed to derive the discrete time transfer function between the absorbed power, $P_{L m}$, and the reference, $P_{G m t}^{*}(26)$, considering $\mathrm{T}_{\mathrm{d}}=\mathrm{T}^{\prime}=\mathrm{T}^{\prime \prime}$. The variables $T_{d}$ and $\omega_{c}$ correspond to the communication timedelay and bandwidth of the local controller of DERs (i.e., $\omega_{c}=2 . \pi .15$, considering an external power loop), respectively.

To evaluate the system stability, three analyses have been performed: 1 ) variation of $T_{d}, 2$ ) variation of $T$, and 3) variation of $M$. The results are shown in Fig. 4.

$$
P_{G m t}^{*}(z)=\frac{P_{L m}(z) \cdot M_{o}(z)}{z+H_{\omega_{c}}(z) \cdot T_{d}(z)\left[1-T_{d}(z)\right] M_{o}(z)} ; M_{o}(z)=\frac{1}{1+\gamma_{o} H_{\pi / M}(z) \cdot z^{M}}
$$

Initially, by mapping the poles (i.e., " $\times$ ") and zeros (i.e., “०”) of the system considering different time-delays, it can be clearly

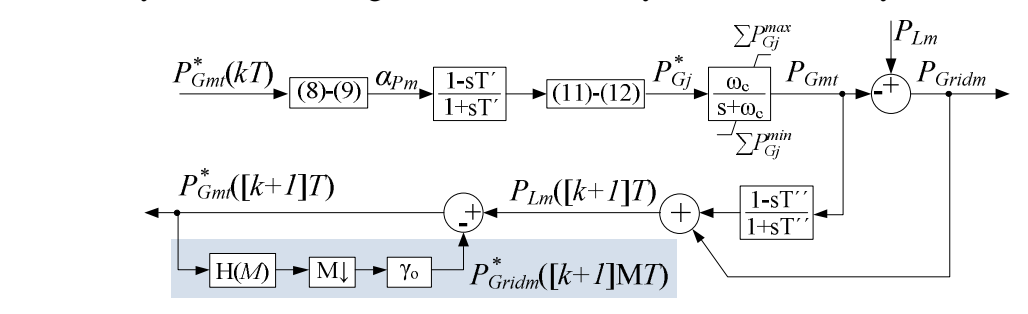

Fig. 3 Simplified model of the microgrid contro seen that $T_{d}, T$, and $M$ distinctively affect the behavior of the model in regard to stability. At first, for the sake of simplicity, in Fig. 4(a) the system is evaluated considering $T_{d}$ varying from $1 / 600 \mathrm{~s}$ up to $1 / 6 \mathrm{~s}$, while considering $T=1 / 60 \mathrm{~s}$, and $M=60$. It is noticed that, since all poles lie within the unit circle, the system is considered stable for all values of $T_{d}$ tested. Thus, by considering that modern communication systems applied to such scenario could present maximum latency of about $100 \mathrm{~ms}$ [35], stability would be maintained. The outcome of having slower transmission times for the data flowing from DERs to MC (i.e., higher $T_{d}$ ) is that the poles of the system tends to move towards the positive real axis, becoming more dominant and consequently presenting more influence on system stability. In addition, as $T_{d}$ becomes higher, the zeros of the system tend to exceed the unit circle. However, the zeros outside the stability region do not affect the overall performance of the system, they potentially introduce non-minimum phase features, which may limit control bandwidth and decrease the phase margin [36].

The case in Fig. 4(b) depicts the influence of increasing $T$. For this result, it is considered $T_{d}=1 / 120 \mathrm{~s}, M=60$, and $T$ varying from $1 / 600 \mathrm{~s}$ to $1 / 6 \mathrm{~s}$. Unlike the previous case, slower transmission times from the MC to DERs introduce a tendency of having dominant poles lying on the negative real axis. With all poles within the unit circle, such condition also does not affect stability, although by being on the left half-plane there is an indication of more oscillatory behavior of the system by nature [36]. This result is reasonable since the time response of the system is directly dependent on the processing/transmission time of the control coefficients calculated by the PBC and which must be broadcasted to DERs to respond adequately. Once again, zeros tend to lie outside the unit circle as the $T$ increases, resulting in similar behavior of that from $T_{d}$.

Finally, the influence of $M$ is seen in Fig. 4(c), where $T_{d}=1 / 120 \mathrm{~s}, T=1 / 60 \mathrm{~s}$, and $M$ varies from 1 to 600 . This particular case demonstrates that $M$ presents less significance on the matter of system stability than $T_{d}$ and $T$. It can be noted that as the delay increases on this communication link, although the poles of the system move toward the positive real axis, they remain practically static, being close to the border of the unitary radius but not extrapolating it. Such condition is noticed since the multiobjective control approach proposed in this work only changes the power references of the PBC algorithm, without affecting the lower level of communication related to $T_{d}$ and $T$. This means that, considering the matter of stability related to communication issues, if the system is stable with any considered time-delays $T_{d}$ and $T$, it shall also be stable when the multiobjective control is integrated to the approach.

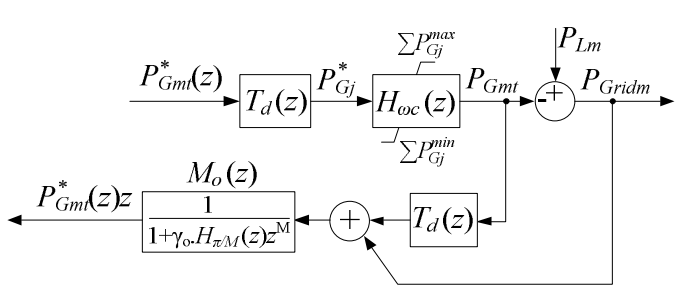

(b)

me power-based control (a) and multiobjective approach (b - active power balance). 

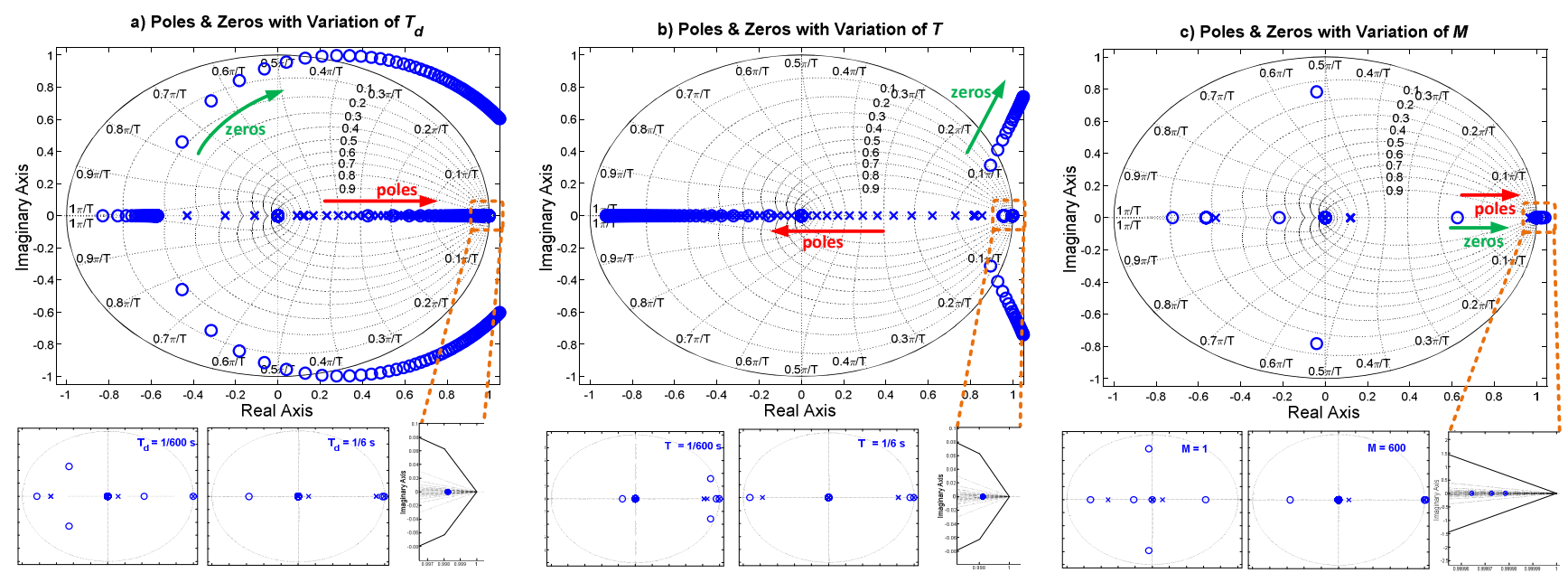

Fig. 4 Pole and zero mapping considering different delays and the system behavior under slower transmission times: variation of (a) $T_{d}$, (b) $T$, and (c) $M$.

\section{Simulation Results}

The assessment of the optimal multiobjective control is presented using the LV MG structure previously described in Section II and shown in Fig. 1. The parameters of the UI and DERs, and maximum loads capacities are shown, respectively, in Table II and Table III. Herein, in order to evaluate the UI contribution to re-circulate power flow among the system phases through its DC link, the UI capacity of contributing to active power during grid-connected mode is set to zero (i.e., it runs similarly to an active power filter or DSTATCOM [7]). Whereas, during islanded operation it is enabled to process active power within its power rating capacity.

The hierarchical control is implemented with the optimal multiobjective approach in the secondary-level layer-2 that is executed once a minute with 7 seconds of processing time (using a i7-7500 CPU @ 2.70GHz and 8GB RAN notebook). While the PBC devised at the secondary-level layer-1 is processed once every fundamental grid voltage cycle (i.e., $16 \mathrm{~ms}$ ). For the sake of simplicity, DERs are realized by ideal current sources, but either current- or voltage-controlled modes could be implemented with power converters, since they just need to be power dispatchable at the fundamental frequency. Fig. 5 shows the adopted 48-hours profile of active power generated by the DERs, as well as the active and reactive power drawn by the loads. Matlab/Simulink is employed to simulate the entire MG, and to process the control and optimization algorithms. Simulations run using the phasor-mode solver.

The effectivity of the multiobjective control associated to the MG structure is tested through four case studies. A) Firstly, the flexibility of choosing weights for the Vikor method in order to prioritize MG operation is discussed. B) Secondly, the operation of the MG is compared considering three consecutive days with very similar power generation/consumption profile, in which the MG runs without optimization and no UI contribution during the first day, with optimization and no UI in second day, and then with the optimization strategy and with UI contribution in the third day. These three cases demonstrate the multiobjective optimization and the UI improvements to the power system operation. $C$ ) The third result evaluates the plugand-play capability of the system, and $D$ ) the last case shows the improvement caused by the interphase power circulation through the UI. In all periods of the simulations, the MG operates connected to the grid, except during 11-13 h and 59$61 \mathrm{~h}$ when it runs in islanded mode.

\section{A. Microgrid Control Under Different Weights}

Ideally, it is expected that all available energy is injected into the grid, while maintaining negligible active unbalance power (i.e., $F G=1$ and $F_{N a}=0$ ), but this is often not possible. Thus, the MG system operator must decide which term to prioritize

TABLE II

DERS AND UI PARAMETERS

\begin{tabular}{|c|c|c|c|c|c|c|}
\hline \multicolumn{3}{|c|}{ Parameters } & UI & \multicolumn{3}{|c|}{$\operatorname{DER}\left(\mathbf{N}_{15}, \mathbf{N}_{23}, \mathbf{N}_{4}, \mathbf{N}_{18}, \mathbf{N}_{9}, \mathbf{N}_{19}\right)$} \\
\hline \multicolumn{3}{|c|}{ Power rating $(\mathrm{kVA})$} & 3 & \multicolumn{3}{|c|}{$(4.0,8.0,4.0,5.0,6.0,9.0)$} \\
\hline \multicolumn{3}{|c|}{ Max. active power capacity $(\mathrm{kW}$} & 0 & \multicolumn{3}{|c|}{$(4.0,8.0,4.0,5.0,6.0,9.0)$} \\
\hline Min. act & e power & pacity $(\mathrm{kV}$ & 0 & \multicolumn{3}{|c|}{$(0.0,0.0,0.0,0.0,0.0,0.0)$} \\
\hline \multicolumn{7}{|c|}{$\begin{array}{c}\text { TABLE III } \\
\text { MAXIMUM LOADS PER NODE }\end{array}$} \\
\hline Node & $P_{L a}^{\max }[W]$ & $\overline{P_{L b}^{\max }[W]}$ & $\overline{P_{L c}^{\max }[W]}$ & $\overline{Q_{L a}^{\max }[V A r]}$ & $\overline{Q_{L c}^{\max }[V A r]}$ & $\overline{Q_{L c}^{\max }[V A r}$ \\
\hline $\mathrm{N}_{1}$ & 270.0 & 635.0 & 635.0 & 508.0 & 254.0 & 254.0 \\
\hline $\mathrm{N}_{2}$ & 100.0 & 0 & 0 & 40.0 & 0 & 0 \\
\hline $\mathrm{N}_{3}$ & 1270.0 & 635.0 & 635.0 & 508.0 & 254.0 & 254.0 \\
\hline $\mathrm{N}_{4}$ & 0 & 2286.0 & 2171.7 & 0 & 1016.0 & 965.2 \\
\hline $\mathrm{N}_{5}$ & 0 & 1447.8 & 1524.0 & 0 & 603.3 & 635.0 \\
\hline $\mathrm{N}_{6}$ & 1016.0 & 1016.0 & 508.0 & 381.0 & 381.0 & 190.5 \\
\hline $\mathrm{N}_{7}$ & 1016.0 & 508.0 & 1016.0 & 381.0 & 190.5 & 381.0 \\
\hline $\mathrm{N}_{8}$ & 508.0 & 2032.0 & 2032.0 & 158.8 & 635.0 & 635.0 \\
\hline $\mathrm{N}_{9}$ & 3429.0 & 1714.5 & 1131.6 & 1270.0 & 635.0 & 419.1 \\
\hline $\mathrm{N}_{10}$ & 335.3 & 1016.0 & 1016.0 & 125.7 & 381.0 & 381.0 \\
\hline $\mathrm{N}_{11}$ & 0 & 0 & 0 & 0 & 0 & 0 \\
\hline $\mathrm{N}_{12}$ & 2000.3 & 2667.0 & 666.8 & 857.3 & 1143.0 & 285.8 \\
\hline $\mathrm{N}_{13}$ & 0 & 698.5 & 698.5 & 0 & 317.5 & 317.5 \\
\hline $\mathrm{N}_{14}$ & 0 & 2032.0 & 508.0 & 0 & 1143.0 & 285.8 \\
\hline $\mathrm{N}_{15}$ & 5588.0 & 2794.0 & 3492.5 & 2794.0 & 1397.0 & 1746.3 \\
\hline $\mathrm{N}_{16}$ & 1047.8 & 1397.0 & 698.5 & 476.3 & 317.5 & 158.8 \\
\hline $\mathrm{N}_{17}$ & 0 & 0 & 0 & 0 & 0 & 0 \\
\hline $\mathrm{N}_{18}$ & 1905.0 & 1905.0 & 952.5 & 762.0 & 762.0 & 381.0 \\
\hline $\mathrm{N}_{19}$ & 419.1 & 1270.0 & 952.5 & 167.6 & 508.0 & 381.0 \\
\hline $\mathrm{N}_{20}$ & 1587.5 & 1270.0 & 1270.0 & 508.0 & 508.0 & 508.0 \\
\hline $\mathrm{N}_{21}$ & 1397.0 & 2095.5 & 2794.0 & 508.0 & 762.0 & 1016.0 \\
\hline $\mathrm{N}_{22}$ & 698.5 & 461.0 & 1397.0 & 317.5 & 209.6 & 635.0 \\
\hline $\mathrm{N}_{23}$ & 0 & 0 & 0 & 0 & 0 & 0 \\
\hline $\mathrm{N}_{24}$ & 1016.0 & 1016.0 & 1016.0 & 381.0 & 381.0 & 381.0 \\
\hline $\mathrm{N}_{25}$ & 422.9 & 635.0 & 1270.0 & 209.6 & 317.5 & 635.0 \\
\hline $\mathrm{N}_{26}$ & 1270.0 & 635.0 & 0 & 508.0 & 254.0 & 0 \\
\hline Total & $26.3 \mathrm{k}$ & $30.2 \mathrm{k}$ & $26.4 k$ & $10.9 \mathrm{k}$ & $12.4 \mathrm{k}$ & $10.8 \mathrm{k}$ \\
\hline
\end{tabular}




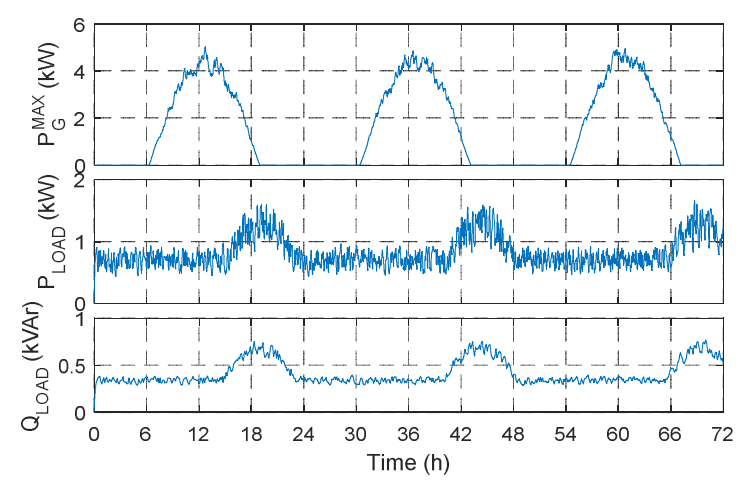

Fig. 5 Power generation profile of PV source (top); Active and reactive load demand profile (bottom).

through setting proper values of weights on the basis of previous knowledge of the system. Fig. 6 shows the $\mathrm{MG}$ operation under three different weights $(W)$ applied to Vikor method, and being analyzed in relation to the PCC voltage, the generation factor (14), and the PCC voltage unbalance index $(F D)$, which is given as $F D(\%)=100 \cdot V_{-} / V_{+}$. Note that these cases are simulated based on the first $24 \mathrm{~h}$ of the power profile in Fig. 5.

The first weight condition is defined by setting precedence of $F G$ over $F_{N a}$ (i.e., $W_{F G}=0.95$ and $W_{F N a}=0.5$ ), with results in Fig. 6(a). The second determines intermediate weights $\left(W_{F G}=W_{F N a}=0.5\right)$ shown in Fig. 6(b). Lastly, Fig. 6(c) gives priority to current unbalance compensation (i.e., $W_{F G}=0.05$ and $\left.W_{F N a}=0.95\right)$. Observing the voltage profiles for every case, it can be noted how, as $W_{F N a}$ prevails, the voltage profile becomes smoother and less divergent among the phases. Besides, it is seen that $F D$ becomes less critical under such condition and $F G$ indicates lower active power injection.

As expected, if $W_{F G}$ increases the active power is extracted significantly, along with the penalty of worsening $F D$ in relation to the other cases. Fig. 6(b) shows that intermediate weights drive the MG to values of $F G$ and $F D$ in the middle point of operation in respect of Figs. 6(a) and 6(c). Hence, it is shown that decision weights ought to be adequately defined upon the operational goals of the MG.

\section{B. Optimal Microgrid Control Considering Multiobjectives}

Three days are considered in this case study as shown in Fig. 7. Initially, the first $0-24 \mathrm{~h}$, the system is evaluated disregarding the optimal multiobjective formulation and

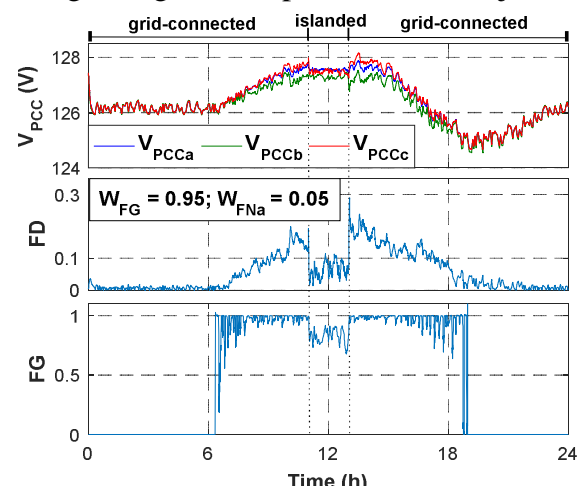

(a)

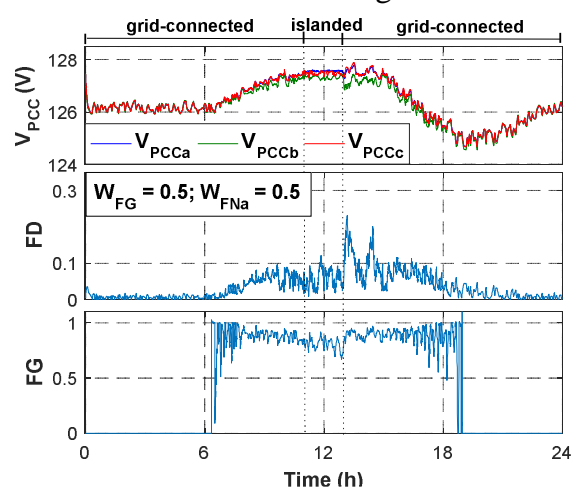

(b) without UI contributions. Hence, DERs inject their maximum active power, and perform sharing of reactive power following the PBC. Note that the $F G$ is practically unitary during the period of high irradiance, except between 11-13 h, when the MG operates isolated from the mains. As a matter of fact, the voltage unbalance would increase if the MG was kept interconnected to the grid, as can be inferred from $F D$ curve in the middle graph of Fig. 7. And, from $Q_{\text {GRIDm }}$ and $\alpha_{Q m}$, respectively in Figs. 8 and 9, it can be seen that reactive power is fully compensated.

During the MG islanded operation, the power sharing is driven by PBC algorithm, and the UI operates imposing the voltage and frequency references to the network. Moreover, upon a condition of greater load demand than DERs capability, or vice-versa, the UI also ensures power balance, delivering or absorbing the remaining portion of power. In this case study, the references of grid and UI are set to zero (i.e., $\left.P_{\text {GRIDm }}^{*}(k+1)=0, P_{\text {UIm }}^{*}(k+1)=0\right)$. This configuration drives the DERs to fully supply the active and reactive power demands, but it is necessary that the UI complements the active and reactive power demanded by phase $b$, once the DERs are saturated, see $\alpha_{P b}$ and $\alpha_{Q b}$ in Fig. 9 synchronized with Fig. 8. It also reduces the $F G$ shown in the bottom graph of Fig. 7 .

In the second operating day, comprising the interval between 24 and $48 \mathrm{~h}$, the optimal multiobjective control is employed, but the UI is disconnected. On the other hand, in the third operating day between 48 and $72 \mathrm{~h}$, the UI contributes to MG operation. The three days follow three weight conditions that are defined based on the previous-known profiles of generation and load:

- \#1) $W_{F G}=0.95$ and $W_{F N a}=0.05$ during $24-35 \mathrm{~h}, 41-59 \mathrm{~h}$ and 65-72 h;

- \#2) $W_{F G}=0.5$ and $W_{F N a}=0.5$ during $35-39 \mathrm{~h}$ and $61-63 \mathrm{~h}$;

- \#3) $W_{F G}=0.05$ and $W_{F N a}=0.95$ during $39-41 \mathrm{~h}$ and 63-65 h.

The set of weights in the second stage of the multiobjective optimization algorithm is kept constant (i.e., $W_{F R N}=0.95$ and $\left.W_{F N r}=0.05\right)$ for the three evaluated operating days. By definition, the reactive power $\left(F R_{N}\right)$ takes precedence over the reactive current unbalance $\left(F N_{r}\right)$ compensation.

During condition $\# 1$, the active power injection is maximized, achieving $F G \approx 1$. This set of weights is applied in the early morning and late afternoon because DERs have small energy availability and, consequently, small contribution to voltage unbalance. Besides, the MG presents light load demand.

Fig. 6 Power quality factors at the PCC, (a) $\mathrm{W}_{\mathrm{FG}}=0.95$ and $\mathrm{W}_{\mathrm{FNa}}=0.05$; (b). $\mathrm{W}_{\mathrm{FG}}=0.5$ and $\mathrm{W}_{\mathrm{FNa}}=0.5$; (c) $\mathrm{W}_{\mathrm{FG}}=0.05$ and $\mathrm{W}_{\mathrm{FNa}}=0.95$.

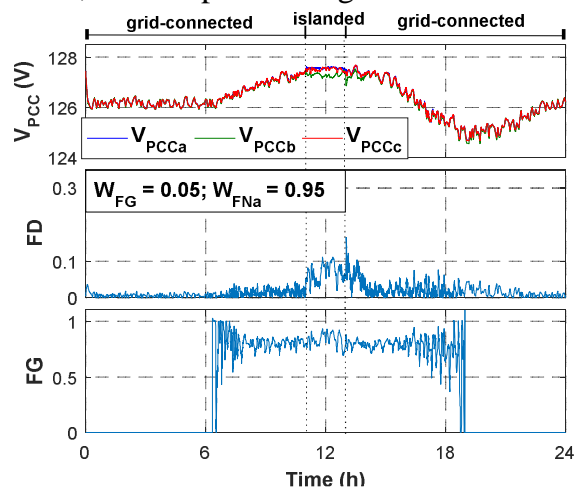

(c) 


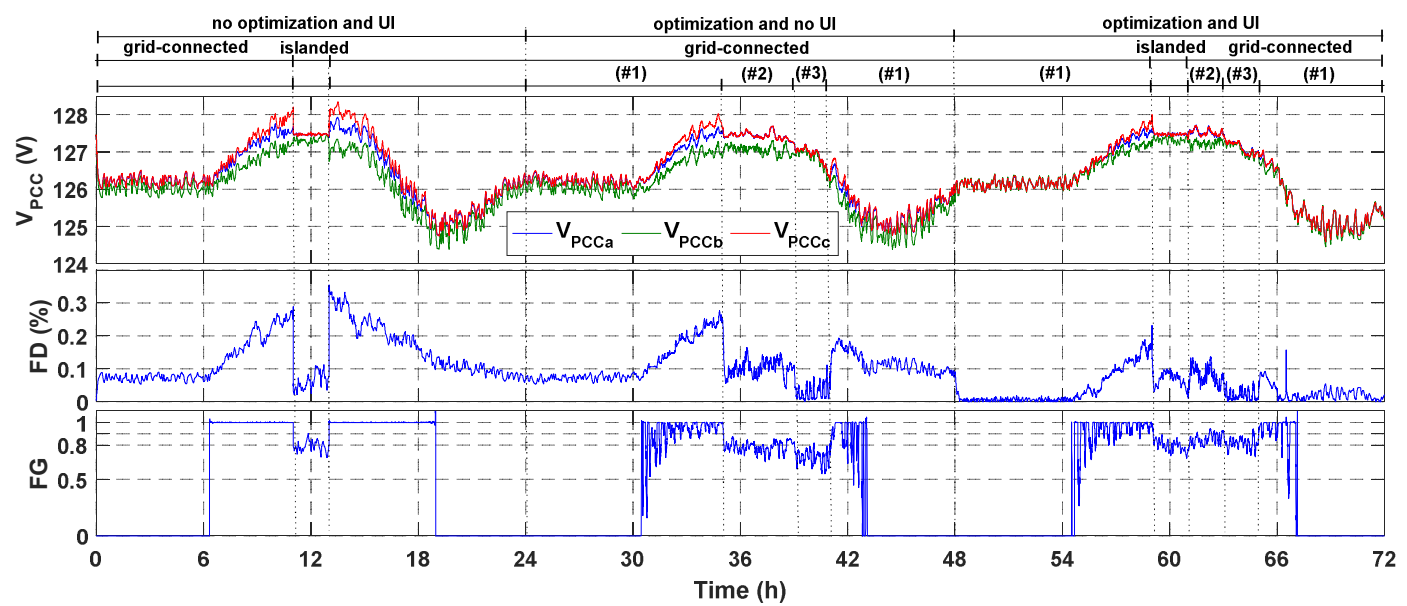

Fig. 7 PCC power quality factors. From top to bottom: PCC phase voltages, factor of voltage unbalance $(F D)$ and generation factor $(F G)$.

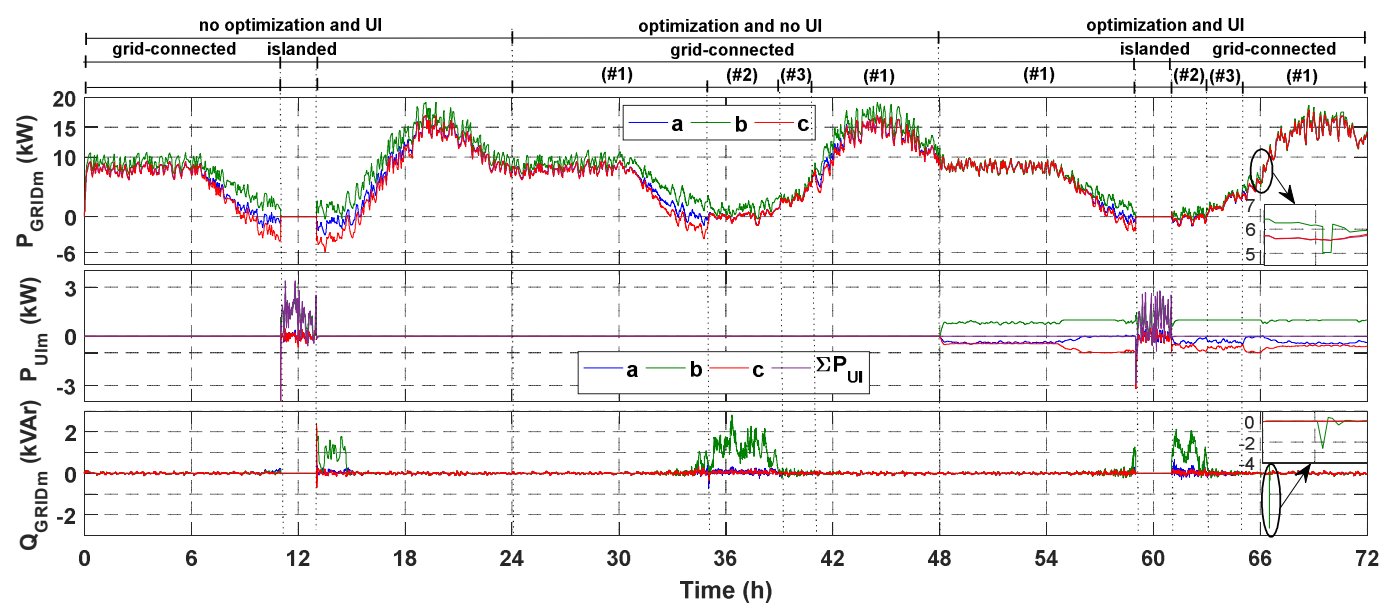

Fig. 8 From top to bottom: active power through the grid and the UI, and reactive power through the main grid.

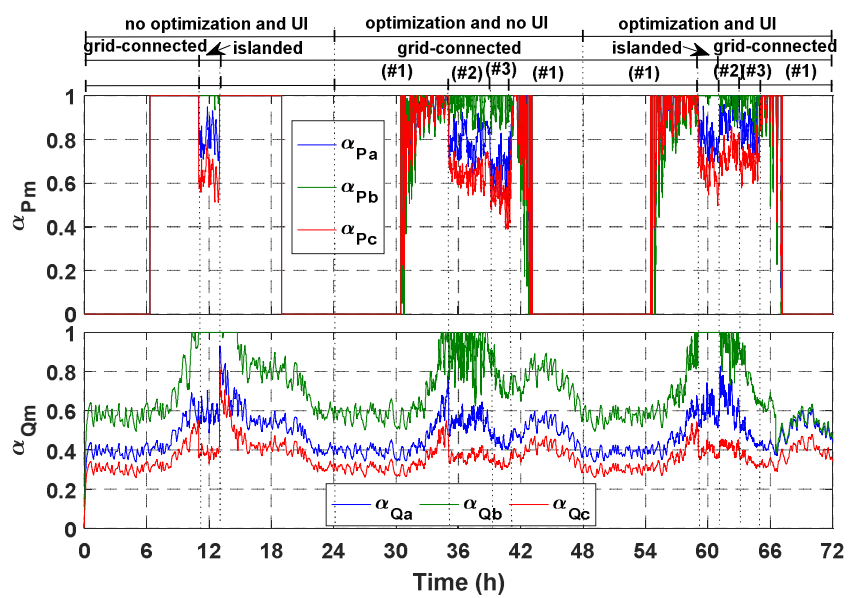

Fig. 9 PBC active (top) and reactive (bottom) scaling coefficients.

Thus, during the intervals $24-32 \mathrm{~h}$ and $43-48 \mathrm{~h}, F D$ is the same as the first day. This fact occurs because the DERs do not have active power injection capacity and the UI is still disconnected. On third day instead, the $F D$ is practically null or very low in the same period of the day, $48-56 \mathrm{~h}$ and $67-72 \mathrm{~h}$ as a consequence of balanced power flow through the grid. This last result is achieved because the UI allows power to circulate from one phase to the other through its DC link. Note that, in the $P_{U I m}$ plot of Fig. 8 , the equivalent three-phase power through the UI, $\Sigma P_{U I}$ (i.e., pink curve), is always null. It shows that, although UI does not process active power, it creates a path for power re-circulation. Moreover, since the $\alpha_{Q m}$ coefficients are not saturated (i.e., not unitary), as seen in Fig. 9, it means that DERs are fully compensating the reactive power.

During the intervals $32-35 \mathrm{~h}$ and $55-59 \mathrm{~h}$, the active power generation increases, which in turn reduces DERs capability to compensate the reactive power and current unbalance. And, the UI power limit is also achieved in third day. Hence, $F D$ increases in value, as shown in Fig. 7. However, the $F D$ value in the third day is better than the second one because the power circulation through the UI allows the multiobjective algorithm to achieve better results in terms of generation and compensation.

Thereupon, the MG runs in islanded mode during the first (11-13 h) and third (59-61 h) day. Comparing both instants, it can be seen that the multiobjective algorithm sets an optimal operation point with practically the same $F D$ value, but relieving the UI power contribution by reducing the peak values, as shown in the middle graph of Fig. 8. In this condition, when the total power produced by the primary source cannot be injected into the grid, recalling that DERs may be endowed with energy storage systems, the exceeding power is stored locally.

Intermediate weights in condition \#2 lead the MG towards moderate level of voltage unbalance by reducing the active power injection ( $F G \cong 0.8$ in Fig. 7 ), even during the maximum 
irradiation period. The equally set of weights is applied in the maximum generation period of the day, because the large capacity of generation, with light load, leads the voltage unbalance to high values (see $F D>0.3 \%$ in the first day of Fig. 7). Compared to the first day, the effectiveness of the optimal control is highlighted by the lower deviation and tighter voltage profile of the three system phases, and by lower value of $F D$ (see Fig. 7, $F D<0.2 \%$ ). Nonetheless, the reactive power is not fully compensated due to the high active power processed by DERs (see $\alpha_{P b}$ in Fig. 9) and to the limited rating capability of UI. Also, since $\alpha_{Q b}$ is saturated, some reactive power circulates in phase $b$ in the grid (see $Q_{G R I D b}$ in Fig. 8). Comparing the third day results with the second one, it is shown that the contribution of the UI reduces the $F D$ values and the saturation of $\alpha_{Q b}$ in Fig. 9. It reduces reactive power propagation to the grid.

The last weight condition, \#3, minimizes $F N_{a}$. This set of weights is applied in a high generation capacity and load demand, once the voltage unbalance can be accentuated. This case shows the lowest level of voltage unbalance, consequently resulting in lower value of active power generation factor $(F D<0.1 \%, \quad F G \approx 0.7$ and $F D<0.05 \%, \quad F G \approx 0.8$, respectively, in second and third day in Fig. 7) compared to the other conditions. Upon the reduction of active power generation, full reactive power compensation is achieved (see $Q_{\text {GRIDm }}=0$ in Fig. 8), confirmed by the non-saturation of $\alpha_{Q m}$ in Fig. 9. The UI contribution to the optimization algorithm is confirmed by the better results, in terms of $F D$ and $F G$, in the third day.

\section{Plug-and-Play Capability}

It is highly desired to attain plug-and-play features, add flexibility to the MG structure, and stand resiliently upon dynamic interconnections of DERs. To test that, a DER is connected at node 24 (phase $b$ ) at $66 \mathrm{~h}$ instant. Initially, such $\mathrm{DER}_{\mathrm{N} 24}$ does not communicate with the $\mathrm{MC}$ and starts injecting its maximum available active power based on its local controller, and not contributing with reactive power. After $30 \mathrm{~min}, \mathrm{DER}_{\mathrm{N} 24}$ communicates with the $\mathrm{MC}$ requesting its participation in the cooperative ancillary services (i.e., PBC) by informing its $m$-phase connection, $X_{m j}$, its rated power (i.e., $A_{G 24}=4 \mathrm{kVA}$ ), and the other data explained in Section II-A.

From $P_{\text {GRIDm }}$ in Fig. 8, the DER $\mathrm{N} 24$ start-up is seen by noting that it causes a step down in $P_{\text {GRIDb }}$ due to its active power injection. Thus, 30 min later, its inclusion in the PBC is seen by noting that $Q_{G r i d b}$ starts to be modulated. The zoom-in-view of Fig. 8, around $66 \mathrm{~h} 30 \mathrm{~min}$, shows a variation in $Q_{\text {Gridb }}$, what means that $\mathrm{DER}_{\mathrm{N} 24}$ is collaborating to mitigate reactive power.

\section{Interphase Power Circulation Through Utility Interface}

The interphase power circulation through the DC link of UI can be seen during the third day in Fig. 8 (see curves $P_{U I m}$ ). Note that the equivalent three-phase power is null during the gridconnected operation (see curve $\Sigma P_{U I}=0$ in Fig. 8), what demonstrates that the UI does not process active power.

The operation point at $39 \mathrm{~h} 36 \mathrm{~min}$, shown in Figs. 7 to 9 , is chosen to highlight the benefits of the interphase power

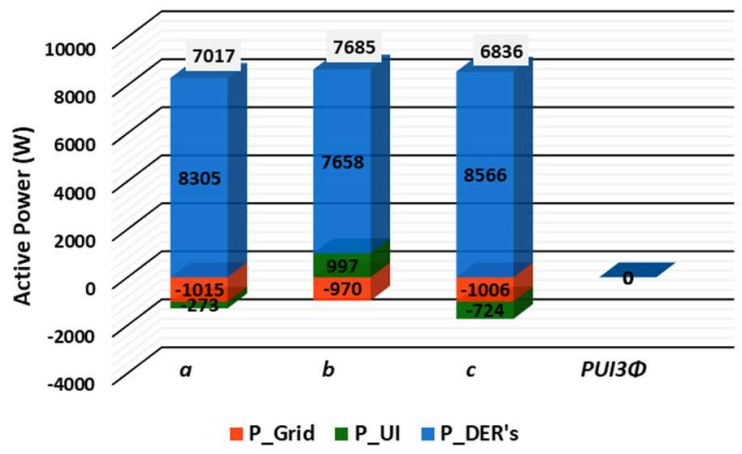

Fig. 10 Active power at the grid side with UI $\left(\mathrm{P}_{\mathrm{UI} 3 \Phi}=\Sigma \mathrm{P}_{\mathrm{UIm}}=0\right)$.

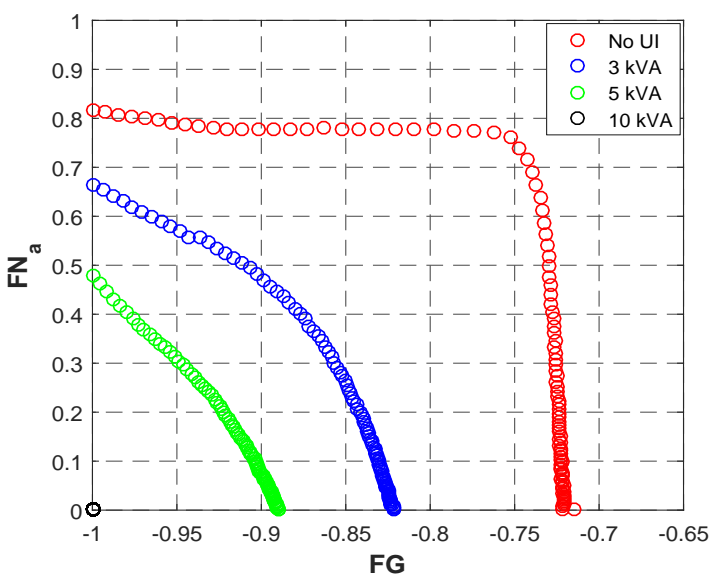

Fig. 11 Pareto-optimal front for different interphase power circulation capabilities depending on the UI rated power.

circulation provided by the UI itself, which is proposed to be performed concomitantly to the multiobjective control approach. To better explain the results of interphase circulation functionality, the following power ratings are reinforced:

- MG active power demand: $P_{L a t}=7017 \mathrm{~W}, P_{L b t}=7685 \mathrm{~W}$, $P_{L c t}=6836 \mathrm{~W}$;

- DERs active power availability: $P_{G a t}^{\max }=9840 \mathrm{~W}$, $P_{G b t}^{\max }=7664 \mathrm{~W}, P_{G c t}^{\max }=12252 \mathrm{~W}$;

- UI capacity: $A_{U I}=3 \mathrm{kVA}$ ( $1 \mathrm{kVA}$ per-phase).

Fig. 10 shows the active power processed per-phase at the grid side (red), by the UI (green), and by DERs (blue). Note that grid power $\left(P_{\text {GRIDm }}\right)$ is practically balanced, regardless of having unbalanced load and uneven generating power from DERs. Besides, the UI steers active power into phase $b$, since it has the heaviest demand $\left(P_{U l b}=997 \mathrm{~W}\right)$, also absorbing power from the other phases $\left(P_{U I a}=-273 \mathrm{~W}\right.$ and $\left.P_{U I c}=-724 \mathrm{~W}\right)$ to maximize the DERs generation, maintaining controllability over the current unbalance. Note that the UI three-phase power is equal to zero (see $P_{U I 3 \emptyset}$ in Fig. 10), indicating that there is no active power being processed by the UI.

Finally, Fig. 11 shows how the Pareto-optimal front changes with different UI capabilities. This Pareto-optimal front is found simulating the UI considering different rated power capacities. The higher the UI rated power, the closer the Paretooptimal front is to the ideal point (i.e., $F G=1$ and $F N_{a}=0$ ). For the considered MG, a UI rated power equal to $10 \mathrm{kVA}$ would fully fulfil the current unbalance compensation while keeping maximum generation factor. 


\section{CONCLUSION}

This paper presents a flexible dispatchable optimal multiobjective control, which is implemented in the secondary level of a hierarchical architecture of microgrid (MG), allowing it to maximize the active power injection from single-phase DERs and to regulate the PCC voltage unbalance level through current compensation. On the basis of a weight decision-maker, the proposed multiobjective formulation is able to dynamically prioritize operational goals such as active power generation (i.e., $F G$ ), unbalance mitigation (i.e., $F N_{a}$ and $F N_{r}$ ), or reactive power compensation (i.e., $F R_{N}$ ). Simulation results show that, by optimizing the system, better performance is achieved in comparison to an operation without the proposed control.

The connection of an UI converter at the MG's PCC enables both grid-connected and islanded modes of operation, and additionally it creates a path for interphase power circulation, which in turn increases the system capability to mitigate unbalance without reducing the active power feed-in when compared to the system without utility interface. The proposed control achieves $i$ ) grid power flow control, ii) PCC power quality enhancement, and iii) plug-and-play capability running under typical operational conditions.

\section{REFERENCES}

[1] A. Hoke, J. Giraldez, B. Palmintier, E. Ifuku, M. Asano, R. Ueda and M. Symko-Davies, "Setting the Smart Solar Standard: Collaborations Between Hawaiian Electric and the National Renewable Energy Laboratory," IEEE Power and Energy Magazine, vol. 16, no. 6, pp. 18-29, Dec. 2018.

[2] J. M. Guerrero, P. C. Loh, T. Lee and M. Chandorkar, "Advanced Control Architectures for Intelligent Microgrids-Part II: Power Quality, Energy Storage, and AC/DC Microgrids", IEEE Trans. Ind. Electron., vol. 60, no. 4, pp. 1263-1270, Apr. 2013

[3] D. I. Brandao, T. Caldognetto, F. Marafão, M. Simões, J. Pomilio, and P. Tenti, "Centralized Control of Distributed Single-Phase Inverters Arbitrarily Connected to Three-Phase Four-Wire Microgrids", IEEE Trans. Smart Grid, vol. 8, no. 1, pp. 437-446, Jun. 2016.

[4] S. Weckx, C. Gonzalez, and J. Driesen, "Combined Central and Local Active and Reactive Power Control of PV Inverters", IEEE Trans. Sustain. Energy, vol. 5, no. 3, pp. 776-784, Mar. 2014.

[5] P. P. Vergara, J. C. López, M. J. Rider, and L. C. P. da Silva, "Optimal Operation of Unbalanced Three-Phase Islanded Droop-Based Microgrids", IEEE Trans. Smart Grid, vol. 10, no. 1, pp. 928-940, Jan. 2019.

[6] P. P. Vergara, J. M. Rey, H. R. Shaker, J. M. Guerrero, B. N. Jørgensen and L. C. P. da Silva, "Distributed Strategy for Optimal Dispatch of Unbalanced Three-Phase Islanded Microgrids", IEEE Trans. Smart Grid, vol. 10, no. 3, pp. 3210-3225, May. 2019.

[7] F. Shahnia and R. P. S. Chandrasena, "A Three-phase Community Microgrid Comprised of Single-phase Energy Resources with an Uneven Scattering Amongst Phases", Int. J. Electr. Power Energy Syst., vol. 84 pp. 267-283, Jan. 2017.

[8] L. He, Y. Li, Z. Shuai and J. M. Guerrero, “A Flexible Power Control Strategy for Hybrid AC/DC Zones of Shipboard Power System with Distributed Energy Storages," IEEE Trans. Ind. Informat., vol. 14, no. 12, pp. $5496-5508$, Dec. 2018.

[9] M. Zeraati, M. E. H. Golshan and J. M. Guerrero, "Voltage Quality Improvement in Low Voltage Distribution Networks Using Reactive Power Capability of Single-Phase PV Inverters," IEEE Trans. Smart Grid, pp. 1-1, Oct. 2018

[10]H. R. Baghaee, M. Mirsalim, G. B. Gharehpetian and H. A. Talebi, “A Generalized Descriptor-system Robust $\mathrm{H}_{\infty}$ Control of Autonomous Microgrids to Improve Small and Large Signal Stability Considering Communication Delays and Load Nonlinearities," Int. J. Elect. Power Energy Syst., vol. 92, pp. 63-82, Nov. 2017.

[11]H. R. Baghaee, M. Mirsalim, G. B. Gharehpetian and H. A. Talebi, "A Decentralized Robust Mixed $\mathrm{H}_{2} / \mathrm{H}_{\infty}$ Voltage Control Scheme to Improve Small/Large-Signal Stability and FRT Capability of Islanded Multi-DER Microgrid Considering Load Disturbances," IEEE Syst. J., vol. 12, no. 3, pp. 2610-2622, Sep. 2018.
[12]H. R. Baghaee, M. Mirsalim, G. B. Gharehpetian and H. A. Talebi, "A Decentralized Power Management and Sliding Mode Control Strategy for Hybrid AC/DC Microgrids including Renewable Energy Resources," IEEE Trans. Ind. Informat., pp. 1-1, Mar. 2017.

[13]H. R. Baghaee, M. Mirsalim, G. B. Gharehpetian and H. A. Talebi, "Unbalanced Harmonic Power Sharing and Voltage Compensation of Microgrids Using Radial Basis Function Neural Network-based Harmonic Power-flow Calculations for Distributed and Decentralised Control Structures," IET Gen. Transm. Dist., vol. 12, no. 7, pp. 1518-1530, Mar. 2018.

[14]L. Meng, F. Tang. M. Savaghebi, J. C. Vasquez and J. M Guerrero, "Tertiary Control of Voltage Unbalance Compensation for Optimal Power Quality in Islanded Microgrids," vol. 29, no. 4, pp. 802-815, Dec. 2014.

[15]G. A. Tinajero, N. L. D. Aldana, A. C. Luna, J. S. Ramírez, N. V. Cruz, J. M. Guerrero and J. C. Vazquez, "Extended-Optimal-Power-FlowBased Hierarchical Control for Islanded AC Microgrids," IEEE Trans. Power. Electron., vol. 34, no. 1, pp. 840-848, Jan. 2019.

[16]P. Tenti, T. Caldognetto, S. Buso, and D. I. Brandao, "Control of Utility Interfaces in Low-voltage Microgrids," Brazilian Power Electron. J., vol. 20, no. 4, pp. 373-382, Nov. 2015.

[17] W. M. Ferreira, D. I. Brandao, F. G. Guimaraes, E. Tedeschi, and F. P. Marafao, "Multiobjective Approach for Power Flow and Unbalance Control in Low-Voltage Networks Considering Distributed Energy Resources", in Proc. Brazilian Power Electron. Conf., Nov. 2017, pp. 1-6.

[18]D. I. Brandao, J. A. Pomilio, T. Caldognetto, S. Buso, and P. Tenti, "Coordinated Control of Distributed Generators in Meshed Low-voltage Microgrids: Power Flow Control and Voltage Regulation", in Proc. 17th Int. Conf. Harmonics Quality Power, Dec. 2016, pp. 249-254.

[19] K. Anderson, K. Burman, T. Simpkins, E. Helson, L. Lisell and T. Case. (2016, Jun.). New York Solar Smart DG Hub-Resilient Solar Project: Economic and Resiliency Impact of PV and Storage on New York Critical Infrastruc. NREL, Golden, CO. [Online]. Available: https://www.nrel.gov /docs/fy16osti/66617.pdf

[20]Communication networks and systems in substations. IEC Std 61850, 2002.

[21] T. Caldognetto, S. Buso, P. Tenti and D. I. Brandao, "A dynamic overvoltage limiting technique for low-voltage microgrids", in 2015 IEEE Energy Conversion Congress and Exposition (ECCE), 2015, p. 23212327.

[22]Y. Han, A. T. Jiang, E. A. A. Coelho and J. M. Guerrero, "Optimal Performance Design Guideline of hybrid reference frame based dual-loop control strategy for stand-alone single-phase inverters," IEEE Transactions on Energy Conversion, vol. 33, no. 2, pp. 730-740, 2018.

[23]Z. Xin, X. Wang, P. C. Loh and F. Blaabjerg, "Grid-Current-Feedback Control for LCL-Filtered Grid Converters With Enhanced Stability," IEEE Transactions on Power Electronics, vol. 32, no. 4, pp. 3216-3228, 2017.

[24]SMA. (2016). Installation - Quick Reference Guide: SMA Flexible Storage System with Battery Backup Function. SMA Solar Technology AG. Niestetal, Germany. [Online]. Available: https://files.sma.de/dl/20472/Ers atzstrom-IS-en-33W.pdf

[25] Schneider. (2015). Conext XW hybrid inverter/charger. Schneider Electric. [Online]. Available: https://www.intermepro.com/fichasproductos/Conext -XW+-Datasheet_ENG.pdf

[26]SMA. (2016). SMA Power Control Module. SMA Solar Technology AG. Niestetal, Germany. [Online]. Available: http://files.sma.de/dl/7680/PCon trolMod-TI-en-12.pdf

[27]P. Tenti, A. Costabeber, P. Mattavelli and D. Trombetti, "Distribution Loss Minimization by Token Ring Control of Power Electronic Interfaces in Residential Microgrids," IEEE Transactions on Industrial Electronics, vol. 59, no. 10, pp. 3817-3826, 2012.

[28]P. Tenti, H. K. M. Paredes, and P. Mattavelli, "Conservative Power Theory, a Framework to Approach Control and Accountability Issues in Smart Microgrids", IEEE Trans. Power Electron., vol. 26, no. 3, pp. 664-673, Mar. 2011.

[29]C. A. C. Coello, G. B. Lamont and D. A. Van Veldhuizen, "MOP Evolutionary Algorithm Approaches", in Evolutionary Algorithms for Solving Multi-Objective Problems, 2th ed., New York: Springer, 2007, p. 63-67.

[30]A. Konak, D. W. Coit and A. E. Smith, "Multi-objective optimization using genetic algorithms: A tutorial," Reliab. Eng. S. Safety, vol. 91, no. 9, pp. 992-1007, Sep. 2006.

[31]A. Trivedi, D. Srinivasan, K. Sanyal, and A. Ghosh, "A Survey of Multiobjective Evolutionary Algorithms Based on Decomposition," IEEE Trans. Evol. Comput., vol. 21, no. 3, pp. 440-462, Jun. 2017. 
[32]C. Deckmyn, T. L. Vandoorn, J. V. de Vyver, J. Desmet and L. Vandevelde, "A Microgrid Multilayer Control Concept for Optimal Power Scheduling and Voltage Control," IEEE Trans. Smart Grid, vol. 9, no. 5, pp. 4458-4468, Sep. 2018.

[33]S. Opricovic and G. H. Tzeng, "Compromise Solution by MCDM Methods: A Comparative Analysis of VIKOR and TOPSIS", Eur. J. Oper. Res., vol. 156, no. 2, p. 445-455, Jul. 2004.

[34]Q. Zhang and H. Li, "MOEA/D: A Multiobjective Evolutionary Algorithm Based on Decomposition," IEEE Trans. Evol. Comp., vol. 11, no. 6, pp. 712-731, Dec. 2007.

[35]A. Angioni, A. Sadu, F. Ponci, A. Monti, D. Patel, F. Williams, D. della Giustina and A. Dedè, "Coordinated Voltage Control in Distribution Grids with LTE Based Communication Infrastructure," in Proc. IEEE Int. Conf. Environ. Elec. Eng., Rome, Italy, 2015, pp. 2090-2095.

[36]K. Ogata, Discrete-time Control Systems, Ed. 2, Prentice-Haal, NJ, 1994.

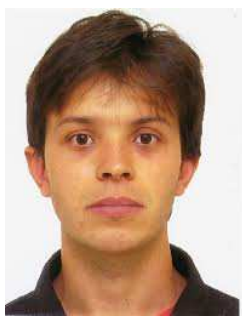

Danilo I. Brandao (S'14-M'16) received the Dr. degree in Electrical Engineering from University of Campinas, Brazil, in 2015. He was a visiting scholar at Colorado School of Mines, USA, in 2009 and in 2013, and at University of Padova, Italy, in 2014, and a guest professor at Norwegian University of Science and Technology, Norway, in 2018. He is currently assistant professor at Federal University of Minas Gerais with the Graduate Program in Electrical Engineering. His main research interests are control of grid-tied converters and microgrids. Mr. Brandao is a member of SOBRAEP and IEEE.

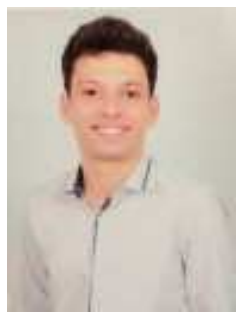

Willian M. Ferreira received the M.S. degree in electrical engineering from Federal University of Minas Gerais, Brazil, in 2018. He has over seven years of experience working in the steel and pulp industry. He is a Professor at the Federal Institute of Minas Gerais, Brazil, since 2016. His research interests include control of active power filter, distributed compensation strategies, and optimization applied to microgrids.

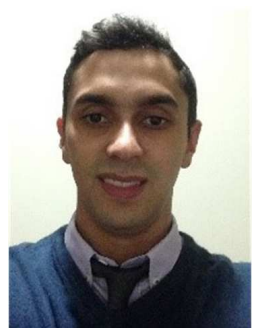

Augusto M. S. Alonso (S'16) received the M.S. degree in Electrical Engineering from the São Paulo State University (UNESP), Brazil, in 2018. Currently, he is working toward a double Ph.D. degree at UNESP and at the Norwegian University of Science and Technology (NTNU), Norway. He was a visiting scholar at the University of New Mexico, USA, during 2012-2013. His main interests are coordinated control of gridtied converters, hierarchical microgrid control, and power quality, and energy policies.

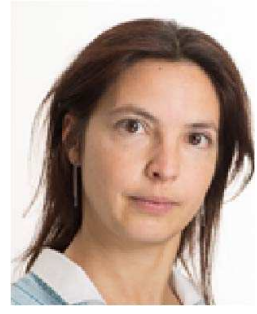

Elisabetta Tedeschi (S'04-M'09) Elisabetta Tedeschi received the M.Sc. degree (with honors) in electrical engineering and the Ph.D. degree in industrial engineering from the University of Padova, Italy, in 2005 and 2009, respectively, working on cooperative control of compensation systems. From 2009 to 2011, she was a Post Doc at the Norwegian University of Science and Technology (NTNU), working on the design and control of energy conversion systems for the grid integration of offshore renewable energies. Having received a Marie Curie Fellowship, she was a Researcher at Tecnalia, Spain, from 2011 to 2013, where she worked on storage solutions for the grid integration of wave energy converters. From 2013 to 2014, she was Research Scientist at SINTEF Energy and Adjunct Associate Professor at NTNU. In 2014, she became Full Professor within offshore grid at NTNU. She has a core competence in the design and control of energy conversion and transmission systems, with focus on offshore energy, and power-quality issues. She has led and/or contributed to more than 15 national and international scientific projects.

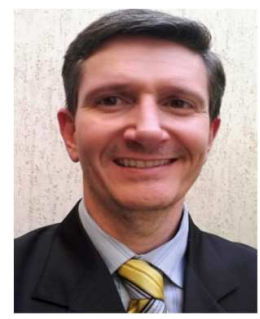

Fernando P. Marafão (S'95-M'05) received the B.S. degree in electrical engineering from UNESP, Brazil, in 1998, and the M.Sc. and Ph.D. degrees from UNICAMP, Brazil, in 2000 and 2004, respectively. In 2002, he joined the Power Electronics Group, University of Padova, Italy, as a visiting student. In 2013, he joined the Colorado School of Mines, USA, as a Visiting Scholar on Autonomous and Intelligent Distributed Energy Systems. Since 2005, he has been with UNESP, as an Associate Professor with the Group of Automation and Integrating Systems. His current research interests include smart grid technologies, renewable energies, energy management and power theories. He is a member of SOBRAEP, SBA and IEEE. 